This document is confidential and is proprietary to the American Chemical Society and its authors. Do not copy or disclose without written permission. If you have received this item in error, notify the sender and delete all copies.

\title{
PEO-b-PCL-b-PMOXA Triblock Copolymers: from Synthesis to Microscale Polymersomes with Asymmetric Membrane
}

\begin{tabular}{|r|l|}
\hline Journal: & Macromolecules \\
\hline Manuscript ID & ma-2016-02743y.R1 \\
\hline Manuscript Type: & Article \\
\hline Date Submitted by the Author: & $19-J a n-2017$ \\
\hline Complete List of Authors: & $\begin{array}{l}\text { Konishcheva, Evgeniia; University of Basel, Chemistry } \\
\text { Zhumaev, Ulmas; Max-Planck-Institut fur Polymerforschung } \\
\text { Meier, Wolfgang; University of Basel, Department of Chemistry }\end{array}$ \\
\hline
\end{tabular}

SCHOLARONE ${ }^{\text {m }}$

Manuscripts 
PEO-b-PCL-b-PMOXA Triblock Copolymers: from Synthesis to Microscale Polymersomes with Asymmetric Membrane

Evgeniia V. Konishcheva ${ }^{\dagger}$, Ulmas E. Zhumaev ${ }^{\dagger}$, Wolfgang P. Meier ${ }^{\dagger *}$

${ }^{\dagger}$ Department of Chemistry, University of Basel, Klingelbergstrasse 80, 4056 Basel, Switzerland

${ }^{*}$ Max Planck Institute for Polymer Research, Ackermannweg 10, 55128 Mainz, Germany

*Corresponding author.

E-mail address: wolfgang.meier@unibas.ch (W. Meier)

\begin{abstract}
We report a new family of amphiphilic ABC triblock copolymers, poly(ethylene oxide)-block-polycaprolactone-block-poly(2-methyl-2-oxazoline) (PEO-b-PCL- $b$ PMOXA). The synthesis is free of toxic reagents, well-controlled, and result in polymers with $\bigoplus_{\mathrm{M}}<1.25$ and PMOXA length up to 25 units $(2 \mathrm{kDa})$. We compare the self-assembly of PEO- $b$ PCL- $b$-PMOXA with PEO- $b$-PCL depending on PCL length and hydrophilic weight fraction $(f)$ using film rehydration method. Polymers self-assemble into different microscale structures, including polymersomes, which were studied by laser scanning microscopy. We proved the asymmetry of polymersome membrane by two independent methods, which confirmed the presence of a longer PEO block and the absence of a shorter PMOXA block on the outer surface of polymersomes.
\end{abstract}

Keywords: PEO- $b$-PCL- $b$-PMOXA, asymmetric copolymer, self-assembly, phase diagram, microscale polymersomes. 
for Table of Contents use only

PEO-b-PCL-b-PMOXA Triblock Copolymers: from Synthesis to Microscale Polymersomes with Asymmetric Membrane

Evgeniia V. Konishcheva ${ }^{\dagger}$, Ulmas E. Zhumaev ${ }^{\ddagger}$, Wolfgang P. Meier ${ }^{\dagger *}$

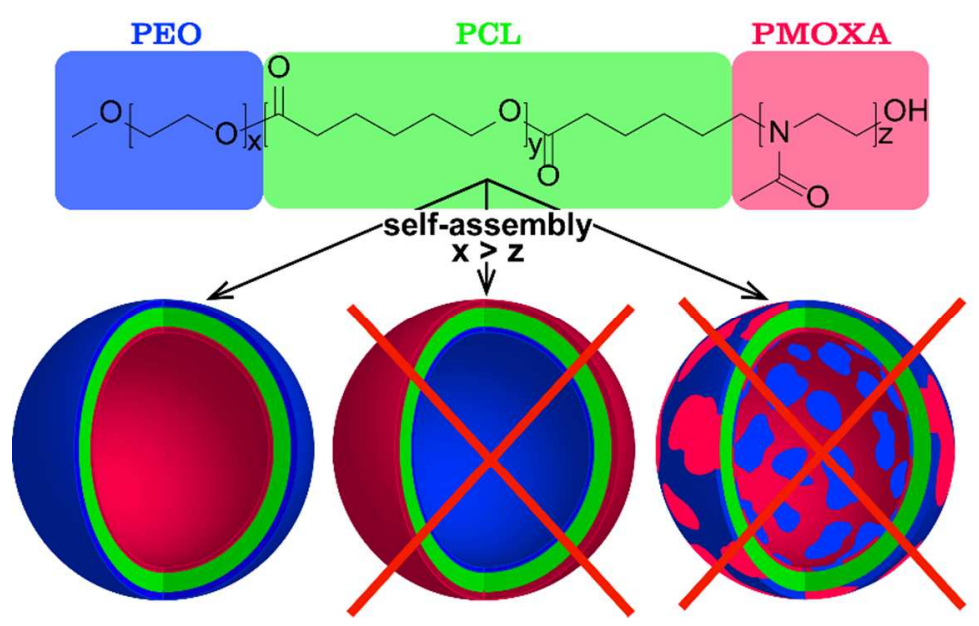




\section{Introduction}

Nature provides a vast variety of fascinating complex structures assembled from different macromolecules. Structures of such assemblies determine their function. A prominent example is a lipid bilayer, which functions as a membrane confining biochemical reactions within a living cell. Artificial membranes assembled from amphiphilic block copolymers exhibit higher chemical and mechanical stability ${ }^{1}$ opening new routes for various bioapplications like drug delivery and nanoreactors..$^{2-7}$ Most of the investigated copolymers have AB or ABA structures, where A - hydrophilic and B - hydrophobic blocks, which self-assemble into symmetric membranes. Recently developed ABC triblock copolymers consisting of two different hydrophilic (A, C) blocks can self-assemble into asymmetric membranes that increases the functionality and flexibility in the design of membranes for bioapplications. For example, ABC membrane induces the directed insertion of membrane proteins ${ }^{8}$ and enhances the delivery of some drugs. ${ }^{9-11}$ Only few studies report the synthesis of ABC asymmetric copolymers. ${ }^{11-17}$ Most of them are obtained via atom transfer radical polymerization ${ }^{11,13-17}$ requiring toxic copper catalyst that may limit bioapplications of such polymers.

In this work, we present a novel asymmetric triblock copolymer consisting of biocompatible blocks, poly(ethylene oxide)-block-polycaprolactone-block-poly(2-methyl-2oxazoline) (PEO- $b$-PCL- $b$-PMOXA). The synthesis is free of toxic agents and well-controlled, yielding polymers with $\bigoplus_{M}<1.25$ and PMOXA length up to 25 units ( $2 \mathrm{kDa}$ ). Furthermore, we present the self-assembly of the synthesized polymers depending on both PCL length and hydrophilic weight fraction $(f)$ using film rehydration method. The polymers form microscale structures, including polymersomes, which were characterized by laser scanning microscopy. We confirm, for the first time, the complete membrane asymmetry of ABC polymersomes. We show 
by two independent methods that only PEO block, which is longer than PMOXA, composes mainly the outer surface of the polymersome membrane. 


\section{Experimental Section}

Materials. Glassware for polymerization was dried overnight at $120{ }^{\circ} \mathrm{C}$ prior to use. Chemicals were obtained from Sigma-Aldrich and used as received unless otherwise mentioned. Milli-Q water $(15 \mathrm{M} \Omega \cdot \mathrm{cm})$ was used from ELGA Purelab Option-R 7/15 system. Polyethylene oxide monomethyl ether (PEO, $2000 \mathrm{~g} \cdot \mathrm{mol}^{-1}$ ) and bifunctional $\mathrm{HC} \equiv \mathrm{C}-\mathrm{CH}_{2}-\mathrm{O}-\mathrm{PEO}-\mathrm{OH}$ (AlkynePEO, $2000 \mathrm{~g} \cdot \mathrm{mol}^{-1}$, Laysan Bio) were dissolved in water and then lyophilized. $\varepsilon$-Caprolactone $(\varepsilon$ CL) was dried over $\mathrm{CaH}_{2}$ and distilled under reduced pressure. Toluene was dried over $\mathrm{CaH}_{2}$ and distilled under argon atmosphere prior to use. Tin(II) 2-ethylhexanoate $\left(\mathrm{SnOct}_{2}\right)$ was distilled under reduced pressure. 2-Methyl-2-oxazoline (MOXA) was dried under argon atmosphere over $\mathrm{CaH}_{2}$ for at least 12 hours and distilled prior to use. Sulfolane was dried over $\mathrm{CaH}_{2}$ for 24 hours under reduced pressure at $35^{\circ} \mathrm{C}$, distilled, and stored in the glove box. 2-Methyl $p$ toluenesulfonate (MeOTs) was dried under vacuum over $\mathrm{CaH}_{2}$ for at least 12 hours and distilled prior to use. Bodipy 630/650 NHS ester was purchased from Thermo Fisher Scientific Inc. SulfoCyanine3 azide and Sulfo-Cyanine3 alkyne were purchased from Lumiprobe.

Microwave-assisted Synthesis. Microwave polymerization was performed on Biotage Initiator System equipped with Robot Eight. The microwave synthesizer operated at a constant set temperature monitored by the IR-sensor.

Nuclear Magnetic Resonance Spectroscopy (NMR). ${ }^{1} \mathrm{H}$ NMR spectra were recorded in $\mathrm{CDCl}_{3}(0.05 \%$ tetramethylsilane) on a Bruker Avance III NMR spectrometer $(400.13 \mathrm{MHz})$. Spectra were processed with MestReNova software, and chemical shifts are reported in ppm.

Gel Permeation Chromatography (GPC). GPC traces were analyzed and recorded in WinGPC (v 8.20 build 4815, PSS systems). The DMF (20 mM LiBr) GPC system was equipped with 3 PSS GRAM columns (one $30 \AA$, two $1000 \AA$, each $30 \mathrm{~cm}$ long, $10 \mu \mathrm{m}$ particles, $0.8 \mathrm{~cm}$ 
diameter) and Viscotek TDA 305 detector system including refractive index (RI), triple UV-Vis operating at different wavelengths $(189-506 \mathrm{~nm})$, light scattering at $90^{\circ}\left(\mathrm{LS} 90^{\circ}, 670 \mathrm{~nm}\right)$, and viscosity (DP) detectors. The samples were measured at $60{ }^{\circ} \mathrm{C}$ with the flow rate of $1 \mathrm{ml} \cdot \mathrm{min}^{-1}$. The system was calibrated against narrowly distributed poly(methyl methacrylate) (PMMA) standards.

Laser Scanning Microscopy (LSM). LSM images were recorded on Zeiss LSM510 META/ConfoCor 2 FCS microscope using a Zeiss Plan-Apochromat 100x/1.4 Oil DIC objective lens. Bodipy 630/650 was excited by the $633 \mathrm{~nm} \mathrm{He-Ne} \mathrm{laser} \mathrm{line} \mathrm{(10 \%} \mathrm{output).} \mathrm{Sulfo-Cy3} \mathrm{was}$ excited by the $514 \mathrm{~nm}$ Argon Laser line (10\%output). Calcein was excited by the $488 \mathrm{~nm}$ Argon laser line (10\% output). The excitation light was passed through a HFT UV 488/543/633 or HFT 405/514 beam splitter. The emission light from Bodipy 630/650 was passed through a LP 650 long pass filter. The emission light from Sulfo-Cy3 was passed through a LP 560 long pass filter. The emission light from calcein was passed through a NFT 545 beam splitter and a BP 474-525 band pass filter. The fluorescence signals were recorded on the photomultiplier tubes. Twelve-bit images with the resolution of $1024 \times 1024$ pixels were acquired at a scan speed of $51.20 \mu$ ser pixel. The pinholes were adjusted accordingly to record maximum signal intensity. $5 \mu$ of a sample was placed onto a glass cover slip $(22 \mathrm{~mm} \times 50 \mathrm{~mm})$ and covered with a round cover slip (Ø $13 \mathrm{~mm}$ ) which was sealed with nail polish. The images were processed with ImageJ (ver. 1.50B) software.

Synthesis of PEO-b-PCL Diblock Copolymers. PEO- $b$-PCL was synthetized using an optimized procedure described in our previous work. ${ }^{18}$ Briefly, PEO (1 eq., 1.0 g, 0.5 mmol) was mixed with $\varepsilon$-CL (500 eq., $28.5 \mathrm{~g}, 0.25 \mathrm{~mol})$ and toluene $(33.5 \mathrm{ml})$ in a three-neck flask. Freshly distilled $\mathrm{SnOct}_{2}(0.1$ eq., $0.5 \mathrm{ml}(0.1 \mathrm{M}$ solution in toluene $))$ was added to the reaction mixture, 
and the mixture was degassed by three freeze-pump-thaw cycles. The polymerization was carried out at $110^{\circ} \mathrm{C}$, and the reaction time varied depending on the targeted length of the PCL block. PEO- $b$-PCL copolymer was precipitated 3 times in cold diethyl ether, and the precipitate was collected by filtration and dried under vacuum. The block ratio was determined by integrating the peak from the terminal methyl group of PEO at $3.38 \mathrm{ppm}$ and the peaks of the PCL backbone at 2.31 and $4.06 \mathrm{ppm}$. The polymers were also characterized by DMF GPC. ${ }^{1} \mathrm{H}$ NMR (400.13 MHz, $\left.\delta, \mathrm{CDCl}_{3}\right): 1.38$ ppm (m, (O)C- $\left.\mathrm{CH}_{2}-\mathrm{CH}_{2}-\mathrm{CH}_{2}-\mathrm{CH}_{2}-\mathrm{CH}_{2}-\mathrm{O}-\right)$, 1.65 ppm (m, (O)C$\left.\mathrm{CH}_{2}-\mathrm{CH}_{2}-\mathrm{CH}_{2}-\mathrm{CH}_{2}-\mathrm{CH}_{2}-\mathrm{O}-\right), 2.31 \mathrm{ppm} \quad\left(\mathrm{t}, \mathrm{J}=7.1 \mathrm{~Hz}, \quad(\mathrm{O}) \mathrm{C}-\mathrm{CH}_{2}-\mathrm{CH}_{2}-\mathrm{CH}_{2}-\mathrm{CH}_{2}-\mathrm{CH}_{2}-\mathrm{O}-\right)$, $3.38 \mathrm{ppm}\left(\mathrm{s}, \mathrm{CH}_{3}-\mathrm{O}-\right), 3.65 \mathrm{ppm}\left(\mathrm{s},-\mathrm{O}-\mathrm{CH}_{2}-\mathrm{CH}_{2}-\mathrm{O}-\right)$, $4.06 \mathrm{ppm}\left(\mathrm{t}, \mathrm{J}=6.5 \mathrm{~Hz},(\mathrm{O}) \mathrm{C}-\mathrm{CH}_{2}-\mathrm{CH}_{2}-\right.$ $\left.\mathrm{CH}_{2}-\mathrm{CH}_{2}-\mathrm{CH}_{2}-\mathrm{O}-\right)$.

Synthesis of PEO-b-PCL-OTs Macroinitiator. PEO- $b$-PCL-OTs was synthetized using an optimized procedure described in our previous work. ${ }^{18}$ In a representative experiment, PEO- $b$ PCL (1 eq., 2 g, 0.15 mmol) and p-toluenesulfonyl chloride (TsCl) (100 eq., 2.81 g, 15 mmol) were added into a two-neck flask and the mixture was dissolved in anhydrous $\mathrm{CH}_{2} \mathrm{Cl}_{2}(28.6 \mathrm{ml})$. The solution was degassed with three freeze-pump-thaw cycles and backfilled with argon. Then anhydrous pyridine (10 eq., $0.12 \mathrm{ml}, 1.5 \mathrm{mmol}$ ) was added, and the reaction was carried out for $12 \mathrm{~h}$ at $25^{\circ} \mathrm{C}$. The mixture was precipitated 3 times in cold diethyl ether, the final precipitate was dissolved in $\mathrm{CH}_{2} \mathrm{Cl}_{2}(30 \mathrm{ml})$ and washed with Milli-Q water $(3 \times 10 \mathrm{ml})$. The $\mathrm{CH}_{2} \mathrm{Cl}_{2}$ phase was dried over $\mathrm{MgSO}_{4}$ overnight, filtered, and the filtrate was dried under vacuum. The percentage of tosylation was determined by integrating the peak from terminal methyl group of PEO at $3.38 \mathrm{ppm}$ and the aromatic doublets at 7.35 and $7.79 \mathrm{ppm}$. The polymers were also characterized by DMF GPC. ${ }^{1} \mathrm{H}$ NMR (400.13 MHz, $\left.\delta, \mathrm{CDCl}_{3}\right): 1.38 \mathrm{ppm}\left(\mathrm{m},(\mathrm{O}) \mathrm{C}-\mathrm{CH}_{2}-\mathrm{CH}_{2}-\mathrm{CH}_{2}-\mathrm{CH}_{2}-\mathrm{CH}_{2}-\right.$ O-), 1.65 ppm (m, (O)C-CH $\left.-\mathrm{CH}_{2}-\mathrm{CH}_{2}-\mathrm{CH}_{2}-\mathrm{CH}_{2}-\mathrm{O}-\right), 2.31 \mathrm{ppm}\left(\mathrm{t}, \mathrm{J}=7.1 \mathrm{~Hz},(\mathrm{O}) \mathrm{C}-\mathrm{CH}_{2}-\mathrm{CH}_{2}-\right.$ 
$\left.\mathrm{CH}_{2}-\mathrm{CH}_{2}-\mathrm{CH}_{2}-\mathrm{O}-\right)$, 2.45 ppm (s, $\mathrm{CH}_{3}-\mathrm{Ph}$ ), 3.38 ppm (s, $\left.\mathrm{CH}_{3}-\mathrm{O}-\right)$, 3.65 ppm (s, -O-CH $\left.\mathrm{CH}_{2}-\mathrm{CH}_{2}-\mathrm{O}-\right)$, $4.02 \mathrm{ppm}\left(\mathrm{t}, J=6.5 \mathrm{~Hz},-\mathrm{CH}_{2}-\mathrm{OTs}\right), 4.06 \mathrm{ppm}\left(\mathrm{t}, J=6.5 \mathrm{~Hz},(\mathrm{O}) \mathrm{C}-\mathrm{CH}_{2}-\mathrm{CH}_{2}-\mathrm{CH}_{2}-\mathrm{CH}_{2}-\mathrm{CH}_{2}-\mathrm{O}-\right)$, $7.35 \mathrm{ppm}(\mathrm{d}, J=8.1 \mathrm{~Hz}, \mathrm{Ph}), 7.79 \mathrm{ppm}(\mathrm{d}, J=8.3 \mathrm{~Hz}, \mathrm{Ph})$.

Synthesis of PEO-b-PCL- $b$-PMOXA Triblock Copolymers. PEO- $b$-PCL- $b$-PMOXA was synthesized using PEO-b-PCL-OTs macroinitiator for cationic ring-opening polymerization of MOXA by microwave-assisted synthesis. PEO-b-PCL-OTs ( 1 eq., $0.5 \mathrm{~g}, 0.04$ mmol) was dissolved in a freshly distilled MOXA (2500 eq., $7.9 \mathrm{ml}, 93 \mathrm{mmol})$, and sulfolane $(10 \mathrm{~g})$ was added in the glove box. The desired volume of the solution was transferred into microwave vials. The vials were sealed in the glove box under argon atmosphere prior to the transfer to the microwave reactor. After the microwave irradiation at $100{ }^{\circ} \mathrm{C}$ the polymerization mixture was cooled down to room temperature. To get the desired PMOXA length, the reaction time was varied from 3 to 15 minutes. To remove sulfolane and residual monomer, the polymerization mixture was placed into a regenerated cellulose dialysis membrane (MWCO 3.5-5 kDa, SpectraPor) and dialyzed against THF: $\mathrm{H}_{2} \mathrm{O}(9: 1)$ mixture for 2 days and THF: $\mathrm{CH}_{2} \mathrm{Cl}_{2}(9: 1)$ mixture for 1 day (solution was exchanged 7 times). The block ratio was determined by integrating the peak from terminal methyl group of PEO at $3.38 \mathrm{ppm}$ and peaks of PMOXA backbone at 2.12 and $3.46 \mathrm{ppm}$. The polymers were also characterized by DMF GPC. ${ }^{1} \mathrm{H}$ NMR (400.13 MHz, $\delta, \mathrm{CDCl}_{3}$ ): 1.38 ppm (m, (O)C-CH2- $\left.\mathrm{CH}_{2}-\mathrm{CH}_{2}-\mathrm{CH}_{2}-\mathrm{CH}_{2}-\mathrm{O}-\right)$, 1.65 ppm (m, (O)C$\left.\mathrm{CH}_{2}-\mathrm{CH}_{2}-\mathrm{CH}_{2}-\mathrm{CH}_{2}-\mathrm{CH}_{2}-\mathrm{O}-\right), 2.12 \mathrm{ppm}\left(\mathrm{m},\left(-\mathrm{N}\left(\mathrm{C}(\mathrm{O}) \mathrm{CH}_{3}\right)-\right), 2.31 \mathrm{ppm}(\mathrm{t}, J=7.1 \mathrm{~Hz},(\mathrm{O}) \mathrm{C}-\right.$ $\left.\mathrm{CH}_{2}-\mathrm{CH}_{2}-\mathrm{CH}_{2}-\mathrm{CH}_{2}-\mathrm{CH}_{2}-\mathrm{O}-\right), 3.38$ ppm (s, $\left.\mathrm{CH}_{3}-\mathrm{O}-\right), 3.46 \mathrm{ppm}\left(\mathrm{m},-\mathrm{N}\left(\mathrm{C}(\mathrm{O}) \mathrm{CH}_{3}\right)-\mathrm{CH}_{2}-\mathrm{CH}_{2^{-}}\right)$, 3.65 ppm (s, -O- $\left.\mathrm{CH}_{2}-\mathrm{CH}_{2}-\mathrm{O}-\right), 4.06 \mathrm{ppm}\left(\mathrm{t}, \mathrm{J}=6.5 \mathrm{~Hz},(\mathrm{O}) \mathrm{C}-\mathrm{CH}_{2}-\mathrm{CH}_{2}-\mathrm{CH}_{2}-\mathrm{CH}_{2}-\mathrm{CH}_{2}-\mathrm{O}-\right)$.

Synthesis of Alkyne-PEO-b-PCL-b-PMOXA and PEO-b-PCL-b-PMOXA-Azide

Triblock Copolymers. Alkyne-PEO- $b$-PCL- $b$-PMOXA was synthesized using the same 
procedure as for PEO- $b$-PCL- $b$-PMOXA, except Alkyne-PEO was used as a macroinitiator. To obtain PEO- $b$-PCL- $b$-PMOXA-Azide, $0.1 \mathrm{~g} \mathrm{NaN}_{3}$ in $1 \mathrm{ml} \mathrm{DMF} \mathrm{was} \mathrm{added} \mathrm{to} \mathrm{the} 10 \mathrm{ml}$ solution of polymerization mixture after microwave-assisted synthesis, and the mixture was incubated for $12 \mathrm{~h}$ at room temperature and dialyzed as described above. ${ }^{1} \mathrm{H}$ NMR Alkyne-PEO- $b$-PCL- $b$ PMOXA (400.13 MHz, $\left.\delta, \mathrm{CDCl}_{3}\right): 1.38 \mathrm{ppm}\left(\mathrm{m},(\mathrm{O}) \mathrm{C}-\mathrm{CH}_{2}-\mathrm{CH}_{2}-\mathrm{CH}_{2}-\mathrm{CH}_{2}-\mathrm{CH}_{2}-\mathrm{O}-\right)$, $1.65 \mathrm{ppm}$ (m, (O)C- $\left.\mathrm{CH}_{2}-\mathrm{CH}_{2}-\mathrm{CH}_{2}-\mathrm{CH}_{2}-\mathrm{CH}_{2}-\mathrm{O}-\right), 2.12 \mathrm{ppm}\left(\mathrm{m},\left(-\mathrm{N}\left(\mathrm{C}(\mathrm{O}) \mathrm{CH}_{3}\right)-\right), 2.31 \mathrm{ppm}(\mathrm{t}, J=7.1 \mathrm{~Hz}\right.$, (O)C- $\left.\mathrm{CH}_{2}-\mathrm{CH}_{2}-\mathrm{CH}_{2}-\mathrm{CH}_{2}-\mathrm{CH}_{2}-\mathrm{O}-\right), 3.46$ ppm (m, -N(C(O) $\left.\left.\mathrm{CH}_{3}\right)-\mathrm{CH}_{2}-\mathrm{CH}_{2}-\right)$, 3.65 ppm (s, -O$\left.\mathrm{CH}_{2}-\mathrm{CH}_{2}-\mathrm{O}-\right), 4.06 \mathrm{ppm}\left(\mathrm{t}, J=6.5 \mathrm{~Hz},(\mathrm{O}) \mathrm{C}-\mathrm{CH}_{2}-\mathrm{CH}_{2}-\mathrm{CH}_{2}-\mathrm{CH}_{2}-\mathrm{CH}_{2}-\mathrm{O}-\right), 4.21 \mathrm{ppm}(\mathrm{d}, J=$ $\left.2.4 \mathrm{~Hz}, \mathrm{HC} \equiv \mathrm{C}-\mathrm{CH}_{2}-\mathrm{O}-\right) .{ }^{1} \mathrm{H}$ NMR PEO- $b$-PCL- $b$-PMOXA-Azide $\left(400.13 \mathrm{MHz}, \delta, \mathrm{CDCl}_{3}\right)$ : $1.38 \mathrm{ppm}\left(\mathrm{m},(\mathrm{O}) \mathrm{C}-\mathrm{CH}_{2}-\mathrm{CH}_{2}-\mathrm{CH}_{2}-\mathrm{CH}_{2}-\mathrm{CH}_{2}-\mathrm{O}-\right), 1.65 \mathrm{ppm}\left(\mathrm{m},(\mathrm{O}) \mathrm{C}-\mathrm{CH}_{2}-\mathrm{CH}_{2}-\mathrm{CH}_{2}-\mathrm{CH}_{2}-\mathrm{CH}_{2}-\right.$ O-), 2.12 ppm (m, (-N(C(O)CH3)-), $2.31 \mathrm{ppm}\left(\mathrm{t}, \mathrm{J}=7.1 \mathrm{~Hz},(\mathrm{O}) \mathrm{C}-\mathrm{CH}_{2}-\mathrm{CH}_{2}-\mathrm{CH}_{2}-\mathrm{CH}_{2}-\mathrm{CH}_{2}-\mathrm{O}-\right)$, $3.28 \mathrm{ppm}\left(\mathrm{t}, J=6.9 \mathrm{~Hz},-\mathrm{N}\left(\mathrm{C}(\mathrm{O}) \mathrm{CH}_{3}\right)-\mathrm{CH}_{2}-\mathrm{CH}_{2}-\mathrm{N}_{3}\right), 3.38 \mathrm{ppm}\left(\mathrm{s}, \mathrm{CH}_{3}-\mathrm{O}-\right), 3.46 \mathrm{ppm}(\mathrm{m}$, $\left.\mathrm{N}\left(\mathrm{C}(\mathrm{O}) \mathrm{CH}_{3}\right)-\mathrm{CH}_{2}-\mathrm{CH}_{2-}\right), 3.65 \mathrm{ppm}\left(\mathrm{s},-\mathrm{O}-\mathrm{CH}_{2}-\mathrm{CH}_{2}-\mathrm{O}-\right), 4.06 \mathrm{ppm}\left(\mathrm{t}, J=6.5 \mathrm{~Hz},(\mathrm{O}) \mathrm{C}-\mathrm{CH}_{2-}\right.$ $\left.\mathrm{CH}_{2}-\mathrm{CH}_{2}-\mathrm{CH}_{2}-\mathrm{CH}_{2}-\mathrm{O}-\right)$.

Reaction between Alkyne-PEO-b-PCL-b-PMOXA / PEO-b-PCL- $b$-PMOXA-Azide Containing Polymersomes and Sulfo-Cyanine3 Azide / Sulfo-Cyanine3 Alkyne. Polymersomes were prepared by mixing in a round-bottom flask $0.2 \mathrm{ml}$ of $17 \mathrm{mg} \cdot \mathrm{ml}^{-1}$ $\operatorname{PEO}(2.0 \mathrm{~K})-b-\mathrm{PCL}(12.5 \mathrm{~K})-b-\mathrm{PMOXA}(0.3 \mathrm{~K})$ dissolved in $\mathrm{CH}_{2} \mathrm{Cl}_{2}$ with $0.1 \mathrm{ml}$ of $2 \mathrm{mg} \cdot \mathrm{ml}^{-1}$ Alkyne-PEO(2.0K)- $b$-PCL(11.4K)- $b$-PMOXA(0.3K) $\quad$ or $\quad \operatorname{PEO(2.0K)-~} b$-PCL(11.7K)- $b$ PMOXA(0.3K)-Azide dissolved in $\mathrm{CH}_{2} \mathrm{Cl}_{2}$ to yield a final concentration of a modified polymer $15 \% . \mathrm{CH}_{2} \mathrm{Cl}_{2}$ solvent was removed by rotary evaporation. After addition of $1 \mathrm{ml}$ of Milli-Q water the samples were stirred at $350 \mathrm{rpm}$ for $24 \mathrm{~h}$ at $60{ }^{\circ} \mathrm{C}$. After cooling the mixture to $25^{\circ} \mathrm{C}$, $30 \mu \mathrm{l}$ of $7 \mathrm{mM}$ aqueous solution of Sulfo-Cy3-Alkyne or Sulfo-Cy3-Azide were added to Azide- 
or Alkyne-containing polymersomes, respectively. Then $50 \mu \mathrm{l}$ of aqueous solution of $10 \mathrm{mM}$ $\mathrm{Cu}(\mathrm{II})$-Bathocuproinedisulfonic acid and $100 \mu \mathrm{l}$ of freshly prepared aqueous solution of $5 \mathrm{mM}$ sodium ascorbate were added, followed by three freeze-pump-thaw cycles and backfilling with argon. The reaction was carried out for $48 \mathrm{~h}$ at $25^{\circ} \mathrm{C}$. After $48 \mathrm{~h}$ approximately $300 \mu \mathrm{l}$ of a reaction mixture was placed into a round bottom flask, water was removed by rotary evaporation, and the sample was dissolved in DMF $(20 \mathrm{mM} \mathrm{LiBr})$ to a final concentration of $2 \mathrm{mg} \cdot \mathrm{ml}^{-1}$, filtered using $0.2 \mu \mathrm{m}$ PTFE filter, and analyzed by DMF GPC.

Synthesis of PMOXA Homopolymers. MeOTs (1 eq., $0.1 \mathrm{ml}, 0.66 \mathrm{mmol})$, the desired amount of freshly distilled MOXA (5 or 45 eq.), and sulfolane (10 g) were mixed in the glove box. The desired volume of the solution was transferred into microwave vials. The vials were sealed in the glove box under argon atmosphere prior to the transfer to the microwave reactor. After the microwave irradiation at $80^{\circ} \mathrm{C}$ for $10 \mathrm{~min}\left(\mathrm{PMOXA}_{5}\right)$ or $30 \mathrm{~min}\left(\mathrm{PMOXA}_{45}\right)$ the polymerization mixture was cooled down to room temperature, and the polymers were precipitated twice in cold diethyl ether. The block ratio was determined by integrating the peak from terminal methyl group at $2.35 \mathrm{ppm}$ and peaks of PMOXA backbone at 2.12 and $3.46 \mathrm{ppm}$. The polymers were also characterized by DMF GPC: $Đ\left(\mathrm{PMOXA}_{5}\right)=1.13, \mathrm{D}\left(\mathrm{PMOXA}_{45}\right)=1.21$. ${ }^{1} \mathrm{H} \quad \mathrm{NMR} \quad\left(400.13 \mathrm{MHz}, \delta, \quad \mathrm{CDCl}_{3}\right): 2.12 \mathrm{ppm} \quad\left(\mathrm{m}, \quad\left(-\mathrm{N}\left(\mathrm{C}(\mathrm{O}) \mathrm{C} H_{3}\right)-\right), 2.35 \mathrm{ppm} \quad\left(\mathrm{s} . \quad \mathrm{CH}_{3^{-}}\right.\right.$ $\left.\mathrm{N}\left(\mathrm{C}(\mathrm{O}) \mathrm{CH}_{3}\right)-\mathrm{CH}_{2}-\mathrm{CH}_{2}-\right), 3.46 \mathrm{ppm}\left(\mathrm{m},-\mathrm{N}\left(\mathrm{C}(\mathrm{O}) \mathrm{CH}_{3}\right)-\mathrm{CH}_{2}-\mathrm{CH}_{2^{-}}\right)$.

Self-assembly. Microscale structures of PEO- $b$-PCL and PEO- $b$-PCL- $b$-PMOXA copolymers were obtained using film rehydration method. $2 \mathrm{mg}$ of a polymer was dissolved in $200 \mu \mathrm{l}$ of $\mathrm{CH}_{2} \mathrm{Cl}_{2}$ and placed in the glass round-bottom flask. $\mathrm{CH}_{2} \mathrm{Cl}_{2}$ was removed by rotary evaporation, and then $1 \mathrm{ml}$ of Milli-Q water was added. The samples were stirred at $350 \mathrm{rpm}$ for $24 \mathrm{~h}$ at $60{ }^{\circ} \mathrm{C}$. For the encapsulation experiments we used $10 \mathrm{mM}$ aqueous solution of calcein 
disodium salt. After self-assembly in the presence of calcein the solution was dialyzed (cellulose ester membrane, MWCO $100 \mathrm{kDa}$, SpectraPor) for three days against Milli-Q water (solution was exchanged 9 times). Solutions of the structures $(50 \mu \mathrm{l})$ were stained with $0.5 \mu 1$ of $0.72 \mu \mathrm{M}$ Bodipy 630/650 dye and characterized by LSM.

Bicinhoninic acid assay (BCA). $50 \mu \mathrm{l}$ of $15 \mathrm{mg} \cdot \mathrm{ml}^{-1}(1 \mathrm{mM})$ polymer samples was incubated with $400 \mu 1$ of BCA solution in a $2.5 \mathrm{ml}$ vial at $25^{\circ} \mathrm{C}(500 \mathrm{rpm})$. After incubating for 2 or $8 \mathrm{~h}$ the samples containing polymers were centrifuged at $13000 \mathrm{~g}$ for $10 \mathrm{~min}$. Then $300 \mu \mathrm{l}$ of a supernatant was transferred into 96-well plate and the absorbance at $562 \mathrm{~nm}$ was measured. Each series consisted of 10 samples. 


\section{Results and Discussion}

\section{Synthesis of PEO-b-PCL-b-PMOXA Triblock Copolymers}

PEO- $b$-PCL- $b$-PMOXA represents a new family of asymmetric triblock copolymers consisting of well-known biocompatible (PEO, PCL, PMOXA) and biodegradable (PCL) blocks, and its synthesis is free of toxic reagents. PEO- $b$-PCL and PEO- $b$-PCL-OTs were synthesized using an optimized procedure described in our previous work. ${ }^{18}$ We chose PEO- $b$-PCL-OTs as a macroinitiator for polymerization of MOXA (Scheme 1), since tosylates are stable, initiate ionic type of polymerization, and result in polymers with a narrow size distribution. ${ }^{19-21}$ Tosylation was performed for $12 \mathrm{~h}$ at $25^{\circ} \mathrm{C}$ using 100-fold excess of $\mathrm{TsCl}$, since 10-fold excess resulted only in $\sim 10 \%$ of $\omega$-modification. Interestingly, the order of mixing of the compounds played a dramatic role: when we dissolved the polymer first and then added the solution of $\mathrm{TsCl}$, tosylation reached only $50 \%$, whereas when we mixed the polymer and $\mathrm{TsCl}$ first and then added the solvent, tosylation reached $100 \%$. Utilization of triethylamine as a base did not result in the tosylated diblock copolymer and led to an increase of high molecular weight shoulder on GPC elugram which was also observed in the case of PCL. ${ }^{22}$ Utilization of pyridine resulted in tosylation, but the solution often turned yellow after addition of pyridine, presumably due to the formation of unstable pyridine radical anion ${ }^{23}$ formed because of the residual tin(II) left after polymerization of $\varepsilon$-CL. After $\sim 30$ min the color always disappeared.

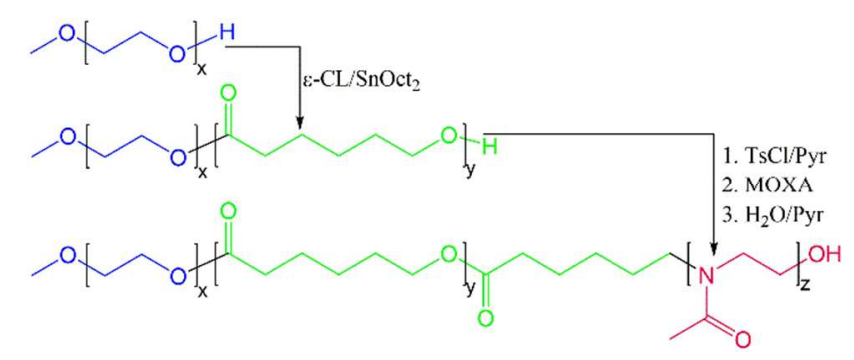

Scheme 1. Synthetic strategy for PEO- $b$-PCL- $b$-PMOXA copolymers. 
We performed MOXA polymerization in a microwave reactor. According to Hoogenboom and co-workers, the microwave-assisted synthesis is advantageous over conventional heating for the polymerization of 2-alkyl-2-oxazolines initiated by alkyl tosylates. $^{21,24-27}$ The formation of PMOXA backbone was confirmed by appearance of the peaks at 2.12 and $3.46 \mathrm{ppm}$ on the ${ }^{1} \mathrm{H}$ NMR spectra (Figure 1A). We optimized the reaction varying the solvent, temperature and reaction time, and MOXA concentration. Sulfolane was more preferable over acetonitrile, a commonly used solvent for MOXA polymerization, since the latter resulted in the slower initiation: ${ }^{1} \mathrm{H}$ NMR spectrum exhibited the presence of both covalently attached tosyl group and tosyl anion (Figure S1). Furthermore, sulfolane accelerates the polymerization of 2-alkyl-2-oxazolines. ${ }^{28}$ 

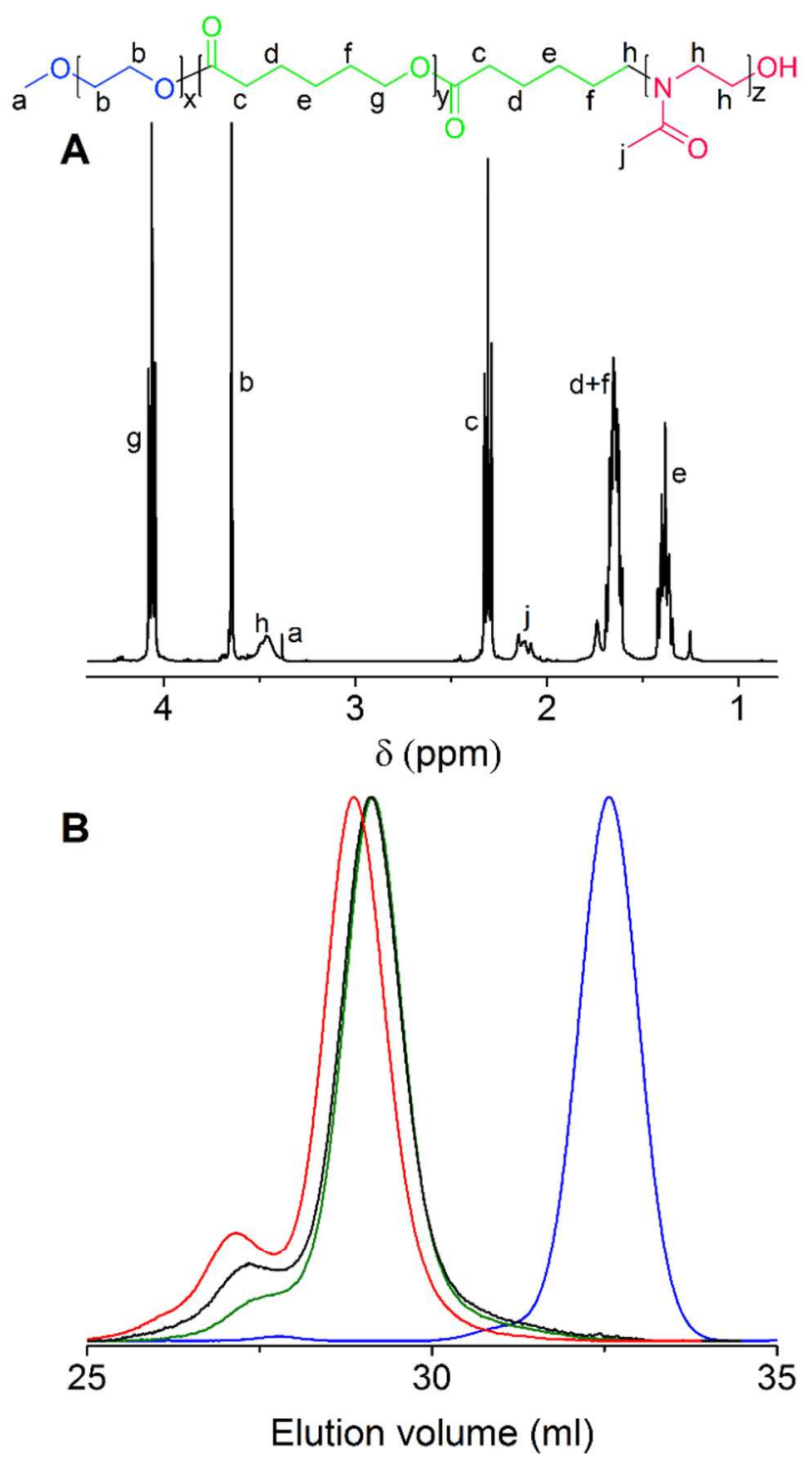

Figure 1. A: representative ${ }^{1} \mathrm{H}$ NMR $\left(\mathrm{CDCl}_{3}\right)$ spectrum of PEO- $b$-PCL- $b$-PMOXA triblock copolymer; B: representative GPC (DMF) traces of PEO (blue, $\bigoplus_{M}=1.08$ ), PEO- $b$-PCL (green, $\bigoplus_{\mathrm{M}}=1.08$ ), PEO- $b$-PCL-OTs (black, $\bigoplus_{\mathrm{M}}=1.11$ ), and PEO- $b$-PCL- $b$-PMOXA (red, $\bigoplus_{\mathrm{M}}=1.14$ ).

High temperatures $\left(140{ }^{\circ} \mathrm{C}, 160^{\circ} \mathrm{C}, 180^{\circ} \mathrm{C}\right)$ at short reaction times $(5-60 \mathrm{sec})$ resulted in the broadening of the corresponding peak on the elugram (Figure S2). This tendency was observed for all tested MOXA concentrations (0.092 M; 0.46 M; 0.92 M; 2.3 M; 11.5 M; 11.8 M (pure MOXA)). The broadening was a result of two side processes: tailing from low molecular 
weight side (formation of PMOXA homopolymer) and shouldering from high molecular weight side due to the chain transfer reactions. ${ }^{29}$ The high molecular weight shoulder mainly consists of PEO- $b$-PCL- $b$-PEO formed during polymerization of $\varepsilon$-CL, as we have shown earlier. ${ }^{18}$ It also might contain some amounts of PEO- $b$-PCL- $b$-PMOXA- $b$-PCL- $b$-PEO, because analogues coupling species were observed in polymerization of 2-alkyl-2-oxazolines. ${ }^{21}$ At $120^{\circ} \mathrm{C}$ and $100^{\circ} \mathrm{C}$ side reactions were also observed (Figure S3), but after longer reaction times (>15 min). At $120^{\circ} \mathrm{C}$ side products accumulated faster compared to $100{ }^{\circ} \mathrm{C}$ (data not shown). Low temperatures $\left(60^{\circ} \mathrm{C}, 80^{\circ} \mathrm{C}\right)$ did not result in the polymerization even after $2-6 \mathrm{~h}$, but induced the growth of high molecular weight shoulder. Consequently, $100{ }^{\circ} \mathrm{C}$ and reaction time up to $15 \mathrm{~min}$ were found to be an optimal temperature and time for the synthesis of PMOXA block due to a relatively low amount of the side products (Figure 1B).

The concentration and storage of MOXA had a big influence on the polymerization kinetics and accumulation of side products. The reaction was much slower when MOXA was stored over $\mathrm{CaH}_{2}$ for $\sim 6$ months prior to distillation compared to $12 \mathrm{~h}$ storage (Figure $\mathrm{S} 4$ ). The effect of MOXA storage on overall kinetics of the polymerization is not clear for us, especially since ${ }^{1} \mathrm{H}$ NMR spectra of MOXA did not reveal any difference (data not shown). Therefore, we used only freshly distilled MOXA stored $<24 \mathrm{~h}$ over $\mathrm{CaH}_{2}$. Increase of MOXA concentration in the polymerization mixture up to $11.5 \mathrm{M}$ (2500 eq.) led to the decrease of the amount of high molecular weight shoulder and homopolymer. With further increase of MOXA concentration (11.8 M, pure MOXA) polymerization rate approached zero presumably due to the low solubility of PMOXA block. ${ }^{28}$ Therefore, all triblock copolymers were obtained by microwave-assisted synthesis in sulfolane using $11.5 \mathrm{M} \mathrm{MOXA}$ at $100{ }^{\circ} \mathrm{C}$ with reaction times up to $15 \mathrm{~min}$. 
The discussed above synthesis has a limitation for obtaining triblock copolymers with PMOXA block length longer than 25 units $(2 \mathrm{kDa})$ while maintaining relatively narrow dispersity $\left(\bigoplus_{M}<1.25\right)$. The synthesis could be improved by using an alternative to tosylated diblock copolymer - nosylated (Nos) macroinitiator, as nosylates result in faster initiation. ${ }^{30}$ However, we were not able to purify PEO- $b$-PCL-ONos while maintaining attached the active end-group.

Combining the previously optimized synthesis of PEO- $b$-PCL-OTs ${ }^{18}$ and newly developed polymerization of MOXA on this macroinitiator, we synthesized a library of narrowly dispersed $\left(\mathrm{Ð}_{\mathrm{M}}=1.10-1.24\right.$, Table 1) PEO- $b$-PCL- $b$-PMOXA copolymers with different PCL and PMOXA lengths to further investigate their self-assembly in aqueous solution.

Table 1. Characterization of PEO- $b$-PCL and PEO- $b$-PCL- $b$-PMOXA copolymers and their microscale self-assembled structures.

\begin{tabular}{|c|c|c|c|}
\hline Copolymer $^{a}$ & $\mathbf{D}_{\mathbf{M}}^{b}$ & $f^{c}, \%$ & Morphology \\
\hline $\mathrm{PEO}(2.0 \mathrm{~K})-b-\mathrm{PCL}(5.5 \mathrm{~K})$ & 1.19 & 27 & S, D \\
\hline $\operatorname{PEO}(2.0 \mathrm{~K})-b-\mathrm{PCL}(5.5 \mathrm{~K})-b-\mathrm{PMOXA}(0.2 \mathrm{~K})$ & 1.16 & 29 & S, D \\
\hline $\mathrm{PEO}(2.0 \mathrm{~K})-b-\mathrm{PCL}(5.5 \mathrm{~K})-b-\mathrm{PMOXA}(0.6 \mathrm{~K})$ & 1.21 & 32 & S, D \\
\hline $\mathrm{PEO}(2.0 \mathrm{~K})-b-\mathrm{PCL}(7.5 \mathrm{~K})$ & 1.15 & 21 & $\mathrm{~S}$ \\
\hline $\operatorname{PEO}(2.0 \mathrm{~K})-b-\mathrm{PCL}(7.5 \mathrm{~K})-b-\mathrm{PMOXA}(0.4 \mathrm{~K})$ & 1.11 & 24 & $\mathrm{P}, \mathrm{S}$ \\
\hline $\mathrm{PEO}(2.0 \mathrm{~K})-b-\mathrm{PCL}(11.7 \mathrm{~K})$ & 1.05 & 15 & $\mathrm{~S}$ \\
\hline $\mathrm{PEO}(2.0 \mathrm{~K})-b-\mathrm{PCL}(11.7 \mathrm{~K})-b-\mathrm{PMOXA}(0.3 \mathrm{~K})$ & 1.14 & 16 & $\mathrm{P}, \mathrm{S}$ \\
\hline $\mathrm{PEO}(2.0 \mathrm{~K})-b-\mathrm{PCL}(11.7 \mathrm{~K})-b-\mathrm{PMOXA}(1.0 \mathrm{~K})$ & 1.12 & 20 & $\mathrm{P}, \mathrm{S}, \mathrm{A}$ \\
\hline $\mathrm{PEO}(2.0 \mathrm{~K})-b-\mathrm{PCL}(11.7 \mathrm{~K})-b-\mathrm{PMOXA}(1.4 \mathrm{~K})$ & 1.13 & 23 & $\mathrm{~A}$ \\
\hline $\operatorname{PEO}(2.0 \mathrm{~K})-b-\mathrm{PCL}(12.5 \mathrm{~K})$ & 1.06 & 14 & $\mathrm{~S}$ \\
\hline $\mathrm{PEO}(2.0 \mathrm{~K})-b-\mathrm{PCL}(12.5 \mathrm{~K})-b-\mathrm{PMOXA}(0.3 \mathrm{~K})$ & 1.12 & 16 & $\mathrm{P}$ \\
\hline $\mathrm{PEO}(2.0 \mathrm{~K})-b-\mathrm{PCL}(15.4 \mathrm{~K})$ & 1.15 & 11 & $\mathrm{~S}$ \\
\hline $\mathrm{PEO}(2.0 \mathrm{~K})-b-\mathrm{PCL}(15.4 \mathrm{~K})-b-\mathrm{PMOXA}(0.3 \mathrm{~K})$ & 1.22 & 13 & $\mathrm{P}, \mathrm{S}$ \\
\hline
\end{tabular}




\begin{tabular}{|c|l|l|c|}
\hline PEO(2.0K)- $b$-PCL(15.4K)- $b$-PMOXA(0.8K) & 1.22 & 15 & S, P \\
\hline PEO(2.0K)- $b$-PCL(15.4K)- $b$-PMOXA(1.7K) & 1.23 & 19 & A, P, S \\
\hline PEO(2.0K)- $b$-PCL(15.4K)- $b$-PMOXA(2.1K) & 1.24 & 21 & A, P, S \\
\hline PEO(2.0K)- $b$-PCL(16.8K) & 1.09 & 11 & S, P \\
\hline PEO(2.0K)- $b$-PCL(16.8K)- $b$-PMOXA(0.3K) & 1.10 & 12 & S, P, I \\
\hline PEO(2.0K)- $b$-PCL(16.8K)- $b$-PMOXA(0.8K) & 1.12 & 14 & I, S, P \\
\hline PEO(2.0K)- $b$-PCL(16.8K)- $b$-PMOXA(1.5K) & 1.11 & 17 & I, S, P \\
\hline PEO(2.0K)- $b$-PCL(17.4K) & 1.08 & 10 & P \\
\hline PEO(2.0K)- $b$-PCL(17.4K)- $b$-PMOXA(0.3K) & 1.13 & 12 & I, S, P \\
\hline PEO(2.0K)- $b$-PCL(17.4K)-b-PMOXA(0.9K) & 1.15 & 14 & S, E \\
\hline
\end{tabular}

${ }^{a}$ Number-average molecular weight of copolymers was determined by ${ }^{1} \mathrm{H}$ NMR spectroscopy.

${ }^{b}$ Dispersity was determined from RI data of samples analyzed by DMF GPC using PMMA calibration. ${ }^{c}$ Hydrophilic weight fraction of PEO (diblocks) and PEO+PMOXA (triblocks) was calculated from ${ }^{1} \mathrm{H}$ NMR data. S - spherical particles, P - polymersomes, I - irregularly shaped particles, E - elongated particles, A - loosely packed aggregates, D - partial dissolution.

\section{Microscale Self-Assembled Structures of PEO-b-PCL-b-PMOXA Triblock Copolymers in}

\section{Aqueous Solution}

Amphiphilic $\mathrm{AB}$ diblock copolymers self-assemble into various structures depending on the length of the hydrophobic B block and hydrophilic weight fraction $(f) .{ }^{31-36}$ However, very little is known about self-assembly of ABC triblock copolymers. To investigate how selfassembly of $\mathrm{ABC}$ copolymers depends on $\mathrm{B}$ length and $f$, we synthesized polymers with one PEO (2 kDa) and different PCL (5.5-17.4 kDa) and PMOXA (0.2-2.1 kDa) block lengths and tested their self-assembly in aqueous solution using film rehydration method. We also compared the structures formed by di- and triblock copolymers to study how addition of the hydrophilic PMOXA block influences self-assembly of the corresponding PEO-b-PCL precursors (Figure 2A, Figure S5, Table 1). The polymers self-assembled into microscale structures which were visualized using LSM. Self-assembly in this case requires high temperatures $\left(\sim 60^{\circ} \mathrm{C}\right)$ due to the 
semicrystalline nature of the PCL block. Film rehydration at $25^{\circ} \mathrm{C}$ did not result in selfassembly even after a week of incubation.

As discussed in the chapter Synthesis of PEO-b-PCL-b-PMOXA Triblock Copolymers, polymers contain high molecular weight side species which might affect self-assembly process. However, the amount of these species is rather low $(\sim 15 \%)$, and they are present in each triblock copolymer. We assume that the effect of these species on self-assembly, if present, is not prevalent over change in PMOXA block length.

The majority of PEO- $b$-PCL copolymers self-assembled into solid spherical particles. Most of PEO- $b$-PCL- $b$-PMOXA copolymers formed a mixture of different structures, and the major morphology depends on $f$, suggesting a strong effect of the PMOXA block length on selfassembly. PEO- $b$-PCL- $b$-PMOXA copolymers with the shortest PCL (5.5 kDa) formed predominantly solid spherical particles. The triblock copolymers with PCL ranging from 7.5 to 15.4 kDa self-assembled mainly into polymersomes (Figure 2B, Figure S5, A-F). However, with the increase of PMOXA block length, and therefore $f$, the triblock copolymers formed loosely packed aggregates suggesting the tendency of a polymer to dissolve (Figure S5, C). The triblock copolymers with the largest PCL $(16.8-17.4 \mathrm{kDa})$ formed predominantly spherical and irregularly shaped particles and some polymersomes (Figure S5, G, J). Only one of the diblock copolymers, PEO(2.0K)-b-PCL(17.4K), formed polymersomes (Figure S5, H), but they were much smaller $(\varnothing<2 \mu \mathrm{m})$ compared to the ones formed by the triblock copolymers $(\varnothing \sim 5 \mu \mathrm{m})$. We assume that this fact can be explained by different membrane structure of polymersomes: the diblock copolymer formed a bilayer membrane, whereas the triblock copolymers assembled into a monolayer. This could be proven by difference in the membrane thickness determined from 
cryoTEM, but in this case assemblies could not be visualized due to the problems with sample preparation caused by the large size of polymersomes.
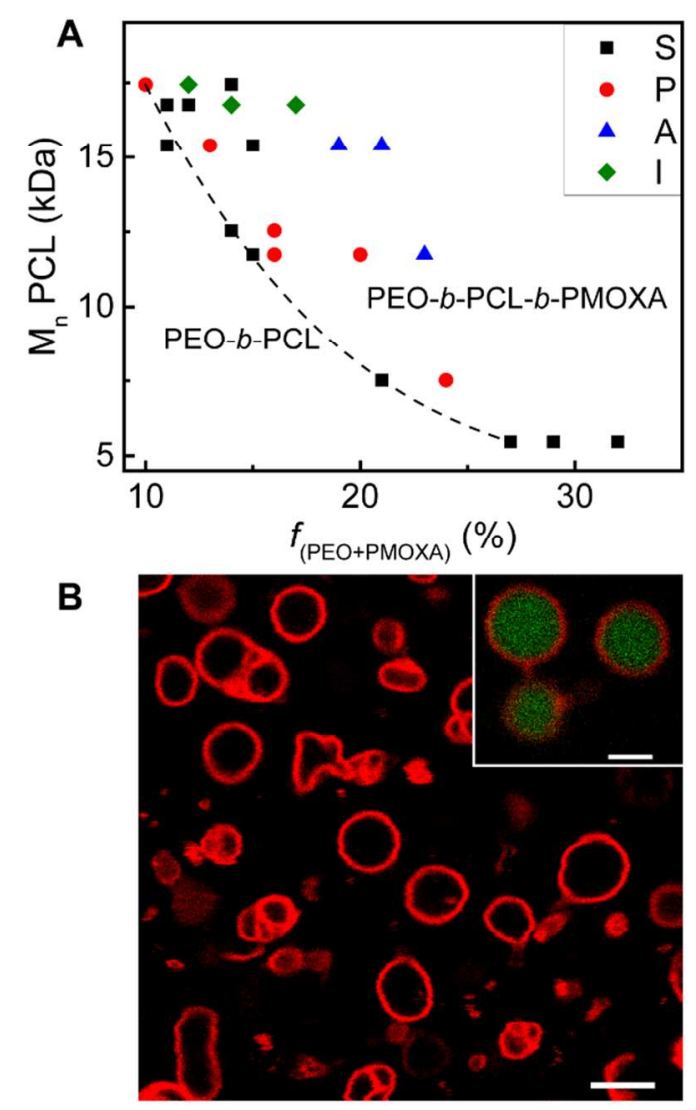

Figure 2. A: Phase diagram of microscale self-assembled structures formed by PEO- $b$-PCL (points on the dashed line) and PEO- $b$-PCL- $b$-PMOXA (points above the dashed line) copolymers using film rehydration method at $60^{\circ} \mathrm{C} . \mathrm{S}-$ spherical particles, $\mathrm{P}$ - polymersomes, A - aggregates, I - irregularly shaped particles. Morphologies were determined qualitatively from LSM images. Most of the systems exhibited mixed morphologies, but to simplify the scheme, only the major component is reported. For more detailed information see Table 1. B: LSM image of polymersomes formed by $\mathrm{PEO}(2.0 \mathrm{~K})-b-\mathrm{PCL}(12.5 \mathrm{~K})-b$-PMOXA(0.3K). Polymersomes were stained with Bodipy 630/650 dye; scale bar is $5 \mu \mathrm{m}$. Inset in the right upper corner represents polymersomes with encapsulated hydrophilic dye calcein; scale bar is $2 \mu \mathrm{m}$. 
Among the obtained self-assembled structures, polymersomes are of a particular interest due to the ability of their membrane to confine aqueous media. As has been shown for symmetric $\mathrm{AB}$ and $\mathrm{ABA}$-based membranes, microscale polymersomes are advantageous for studying the properties of such membranes. ${ }^{37} \mathrm{ABC}$ microscale polymersomes are especially intriguing due to the possibility to have an asymmetric membrane. To test the asymmetry in the case of PEO- $b$ PCL- $b$-PMOXA polymersomes, we took $\mathrm{PEO}(2.0 \mathrm{~K})-b-\mathrm{PCL}(12.5 \mathrm{~K})-b-\mathrm{PMOXA}(0.3 \mathrm{~K})$ as it yielded the most robust formation of polymersomes (Figure 2B, Figure S5, D), which were stable after 6 months of storage at room temperature.

\section{Orientation of PEO-b-PCL-b-PMOXA Chains in the Membrane of Polymersomes}

Polymersomes formed by ABC copolymers with two different hydrophilic blocks (A, C) can potentially have 3 different orientations of hydrophilic blocks: A outside, C outside, mixed A and $\mathrm{C}$ (Scheme 2). When $\mathrm{A}$ and $\mathrm{C}$ blocks have different lengths, the longer one should prefer to segregate on the outer surface of the membrane due to a larger radius of curvature, and the shorter one should be inside. Such orientation of A and C blocks leads to an asymmetric membrane. There were few methods reported for testing the asymmetry of a polymersome membrane. Measurement of $\zeta$ potential at different $\mathrm{pH}$ can be a suitable method when one of the blocks, A or C, is charged. ${ }^{9,11,13-15}$ However, this method does not exclude the possibility to have a membrane with a mixture of both hydrophilic blocks inside and outside (Scheme $2 \mathrm{c}) .{ }^{1} \mathrm{H}$ NOESY NMR was used to determine 3D spatial correlations and hydrogen bonding interactions between two hydrophilic blocks in the case of nanoscale polymersomes, ${ }^{10,38}$ but for our system the latter method did not give a reliable signal presumably because of the micron size of polymersomes. To show the presence of a longer PMOXA block on the surface of PEO- $b$ PDMS- $b$-PMOXA polymersomes, the polymer was modified before its self-assembly with a 
fluorescent dye on PMOXA end, and the quencher of the fluorescent dye was added to the solution of aggregates after self-assembly. ${ }^{12}$ However, this approach did not exclude the presence of PEO outside and the possibility of the inversion of PMOXA block by a bulky dye. To avoid these issues and prove the asymmetry of PEO- $b$-PCL- $b$-PMOXA microscale polymersomes, we used a reaction between polymersomes with functional end-groups on PEO or PMOXA sides and a fluorescent dye. We chose $\mathrm{Cu}$-catalyzed alkyne-azide coupling reaction, as it proceeds under ambient conditions. To get alkyne group on PEO side, we used bifunctional Alkyne-PEO as a precursor for triblock copolymer, since alkyne group was inert in the subsequent steps of the synthesis. Azide functionality on PMOXA terminus was obtained by quenching the polymerization of MOXA with $\mathrm{NaN}_{3}$. The end-group modifications did not affect the dispersity of polymers (Figure S6), and alkyne/azide groups were stable under self-assembly conditions (Figure S7). As a reactive fluorescent dye, we chose Sulfo-Cy3-Alkyne/Azide as it is highly soluble in water and does not pass through a semicrystalline hydrophobic polymersome membrane due to the presence of charged sulfo groups (Figure S8).

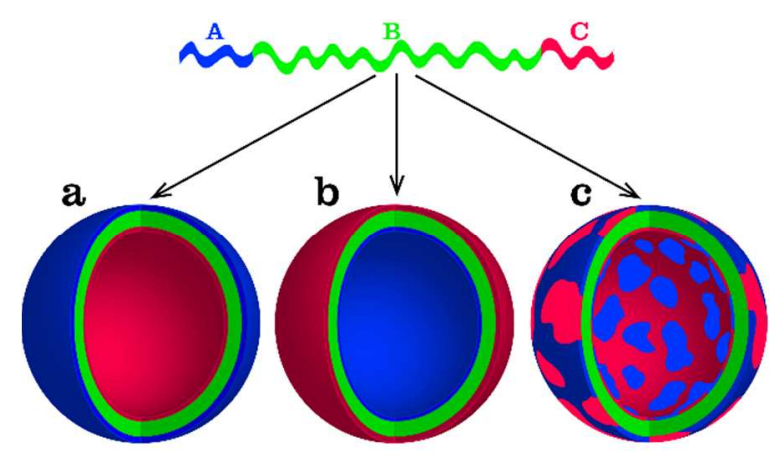

Scheme 2. Possible composition of the membrane of polymersomes formed by ABC copolymer: a: A outside; b: C outside; c: A and C form a mixed membrane.

$\operatorname{PEO}(2.0 \mathrm{~K})-b-\mathrm{PCL}(12.5 \mathrm{~K})-b-\mathrm{PMOXA}(0.3 \mathrm{~K})$ was chosen to test the orientation of polymer molecules in the membrane of polymersomes as it yielded the most robust formation of 
polymersomes (Figure 2B, Figure S5, D). The polymer was mixed with $15 \%$ of AlkynePEO(2.0K)- $b$-PCL(11.4K)- $b$-PMOXA(0.3K) or $\quad \mathrm{PEO}(2.0 \mathrm{~K})-b-\mathrm{PCL}(11.7 \mathrm{~K})-b$-PMOXA(0.3K)Azide, which by itself formed a mixture of polymersomes and spherical particles. The final mixtures yielded polymersomes suggesting that the addition of the alkyne/azide-modified polymers did not disturb the self-assembly (Figure S9). After the reaction between polymersomes and a dye, we were not able to remove the free dye completely by dialysis, SEC on sepharose column, or centrifugal filtration. To check whether the polymersomes reacted with a dye, water was removed by rotary evaporation and the mixture was dissolved in DMF (20 mM $\mathrm{LiBr}$ ) solvent for GPC analysis. The elugrams were analyzed using different detectors. RI and DP detectors were chosen as reference detectors, since they should not be sensitive to such a low concentration of the attached dye. On the contrary, LS $90^{\circ}$ and UV-Vis detectors should give an increased response in the case of the covalently attached dye. Figure 3A, C corresponds to the ABC-Azide containing polymersomes, and $\mathrm{B}, \mathrm{D}-$ to the Alkyne-ABC containing polymersomes. In the case of $\mathrm{ABC}$-Azide containing polymer both sample (reaction mixture) and control (reaction mixture without a catalyst) showed similar detector responses (Figure 3A, C, Figure S10, A), which indicates that PMOXA forms the inner side of polymersomes (Scheme 2a). Alkyne-ABC sample showed major differences between the sample and the control on LS $90^{\circ}$ detector (Figure 3B), UV-Vis $300 \mathrm{~nm}$ (Figure 3D), and UV-Vis $506 \mathrm{~nm}$ (Figure S10, B), suggesting the presence of PEO on the outer surface of polymersomes (Scheme 2a). The increase in the LS $90^{\circ}$ signal is caused by the fluorescence of the covalently attached dye. Note, that LS $90^{\circ}$ signal fluctuates from injection to injection even for the same sample, and the difference between sample and control is not significant in the case of Figure 3A. On the contrary, UV-Vis detector gives a reproducible signal, and the difference between samples is significant. The 
reaction was performed the second time, and the results were identical (Figure S11). Since no increase in the detector response was observed for the ABC-Azide containing polymersomes after reaction with the dye as compared to the increase in signal for the Alkyne-ABC containing polymersomes, the PEO block shows to be preferentially oriented on the outer surface of the polymersomes.
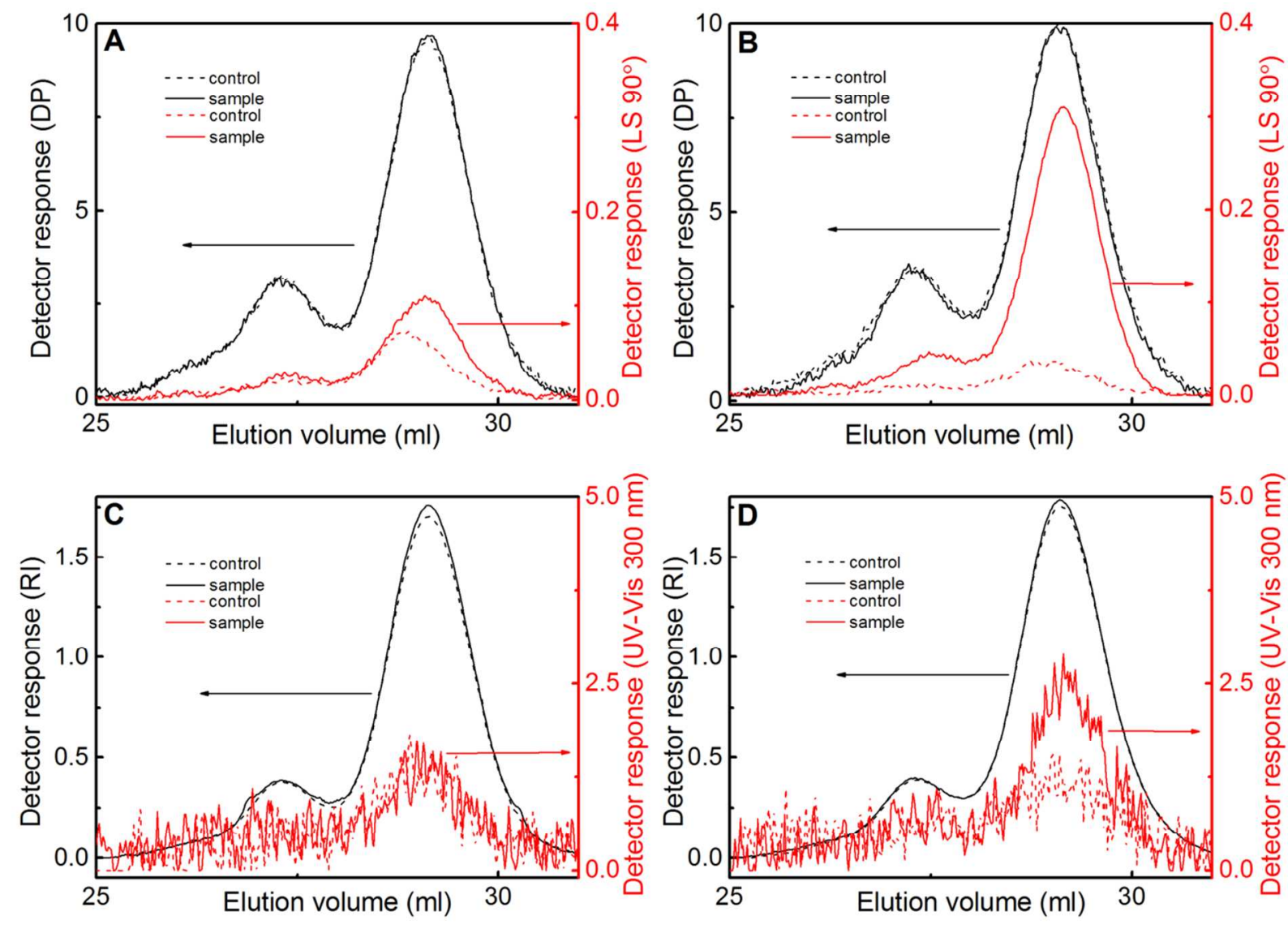

Figure 3. GPC (DMF) traces recorded on DP/LS $90^{\circ}(\mathrm{A}, \mathrm{B})$ and $\mathrm{RI} / \mathrm{UV}-\mathrm{V}$ is $(300 \mathrm{~nm})(\mathrm{C}, \mathrm{D})$ detectors of a mixture after reaction between alkyne/azide containing polymersomes and azide/alkyne-dye: A, C: $85 \% \operatorname{PEO}(2.0 \mathrm{~K})-b$-PCL(12.5K)-b-PMOXA(0.3K) + $15 \% \operatorname{PEO(2.0K)-~}$ $b$-PCL(11.7K)- $b$-PMOXA(0.3K)-Azide + Sulfo-Cy3-Alkyne; B， D: $85 \%$ PEO(2.0K)- $b$ PCL(12.5K)- $b$-PMOXA(0.3K) + $15 \%$ Alkyne-PEO(2.0K)- $b$-PCL(11.4K)- $b$-PMOXA(0.3K) + Sulfo-Cy3-Azide. "Controls" were obtained from the reaction mixture which did not contain 
$\mathrm{Cu}(\mathrm{II})$ complex and sodium ascorbate. "Samples" corresponded to the reaction mixture which contained $\mathrm{Cu}$ (II) complex and sodium ascorbate. The samples for GPC analysis were prepared by removing water from the reaction mixture and dissolving them in DMF (20 $\mathrm{mM} \mathrm{LiBr})$ to a final concentration of $2 \mathrm{mg} \cdot \mathrm{ml}^{-1}$ followed by filtration.

To check whether this reaction can be more favorable in the case of Alkyne-ABC compared to $\mathrm{ABC}$-Azide containing polymersomes, we prepared mixtures containing $50 \%$ of Alkyne-ABC or $\mathrm{ABC}$-Azide and incubated them at $60{ }^{\circ} \mathrm{C}$ for $24 \mathrm{~h}$ before the reaction with a dye. The reaction in both cases yielded the polymer with a covalently attached dye (Figure S12), thus excluding the assumption of a more favourable reaction conditions for alkyne-containing polymersomes.

In addition to the approach discussed above, we tested the asymmetry using a difference in the chemical structures of PEO and PMOXA. We chose bicinhoninic acid assay (BCA) used for measuring peptide concentration ${ }^{39}$ to detect PMOXA, since PMOXA, like peptides, contains amide bonds. This assay is based on the reduction of $\mathrm{Cu}^{2+}$ to $\mathrm{Cu}^{1+}$ by a peptide bond in alkaline medium and its further complexation with bicinhoninic acid yielding a purple complex with a maximum of absorbance at $562 \mathrm{~nm}$. Incubation of PEO and PMOXA containing similar number of repeating units $(\sim 45)$ with $\mathrm{BCA}$ solution for $24 \mathrm{~h}$ at $25^{\circ} \mathrm{C}$ resulted in much higher signal of $\mathrm{PMOXA}_{45}$ samples compared to $\mathrm{PEO}_{45}$ (Figure S13, A). The response of $\mathrm{PMOXA}_{5}$ (which corresponds to the length of PMOXA block in the triblock copolymer) is much lower compared to $\mathrm{PMOXA}_{45}$ (Figure S13, B), which can be explained by the necessity of the presence of a few amide bonds to coordinate $\mathrm{Cu}$ ions. At the low concentrations $(0.1-5 \mathrm{mM})$ of $\mathrm{PMOXA}_{5}$ and $\mathrm{PEO}_{45}$ (which corresponds to the length of PEO block in the triblock copolymer), PMOXA yielded higher signal compared to $\mathrm{PEO}_{45}$, whereas at higher concentrations $(>25 \mathrm{mM}) \mathrm{PEO}_{45}$ 
resulted in higher absorbance values. Therefore, $1 \mathrm{mM}\left(15 \mathrm{mg} \cdot \mathrm{ml}^{-1}\right) \mathrm{ABC}$ concentration was chosen to determine if PMOXA block formed inner or outer part of the membrane of polymersomes. We incubated $\mathrm{AB}$ suspension, $\mathrm{ABC}$ polymersomes, and $\mathrm{ABC}$ suspension with BCA solution for $2 \mathrm{~h}$ at $25^{\circ} \mathrm{C}$, since polymersomes were not stable already after $8 \mathrm{~h}$ (Figure 4D), and the absorbance of $1 \mathrm{mM} \mathrm{PMOXA}_{5}$ sample $(0.123 \pm 0.002)$ was still higher than that of $1 \mathrm{mM}$ $\mathrm{PEO}_{45}(0.115 \pm 0.004)$ under these conditions. We compared the absorbance of the supernatant of the samples without the background subtraction, since our aim was to determine only a difference between the samples. The sample with ABC suspension after $2 \mathrm{~h}$ exhibited higher absorbance value $(0.226 \pm 0.031)$ than $\mathrm{PMOXA}_{5}(0.123 \pm 0.002)$, which can be explained by more efficient coordination of $\mathrm{Cu}$ ions by "concentrated" PMOXA chains in the case of non-soluble ABC suspension. The sample with $\mathrm{ABC}$ polymersomes had higher absorbance than $\mathrm{AB}$ suspension, but lower than $\mathrm{ABC}$ suspension. The latter can be explained by two possible reasons: either some of the PMOXA chains are located on the outer surface of the polymersomes, or the polymersomes get partially permeabilized under these conditions. The latter hypothesis seemed to play a predominant role, since polymersomes might be destabilized due to the osmotic pressure, and polymer (presumably PCL block) is slightly hydrolyzed under these conditions (Figure S14). Based on the Student's t-test, the mean values of the samples with ABC polymersomes and $\mathrm{ABC}$ suspension after $2 \mathrm{~h}$ were significantly different, whereas after $8 \mathrm{~h}$ the mean absorbance was comparable (Table S1). 

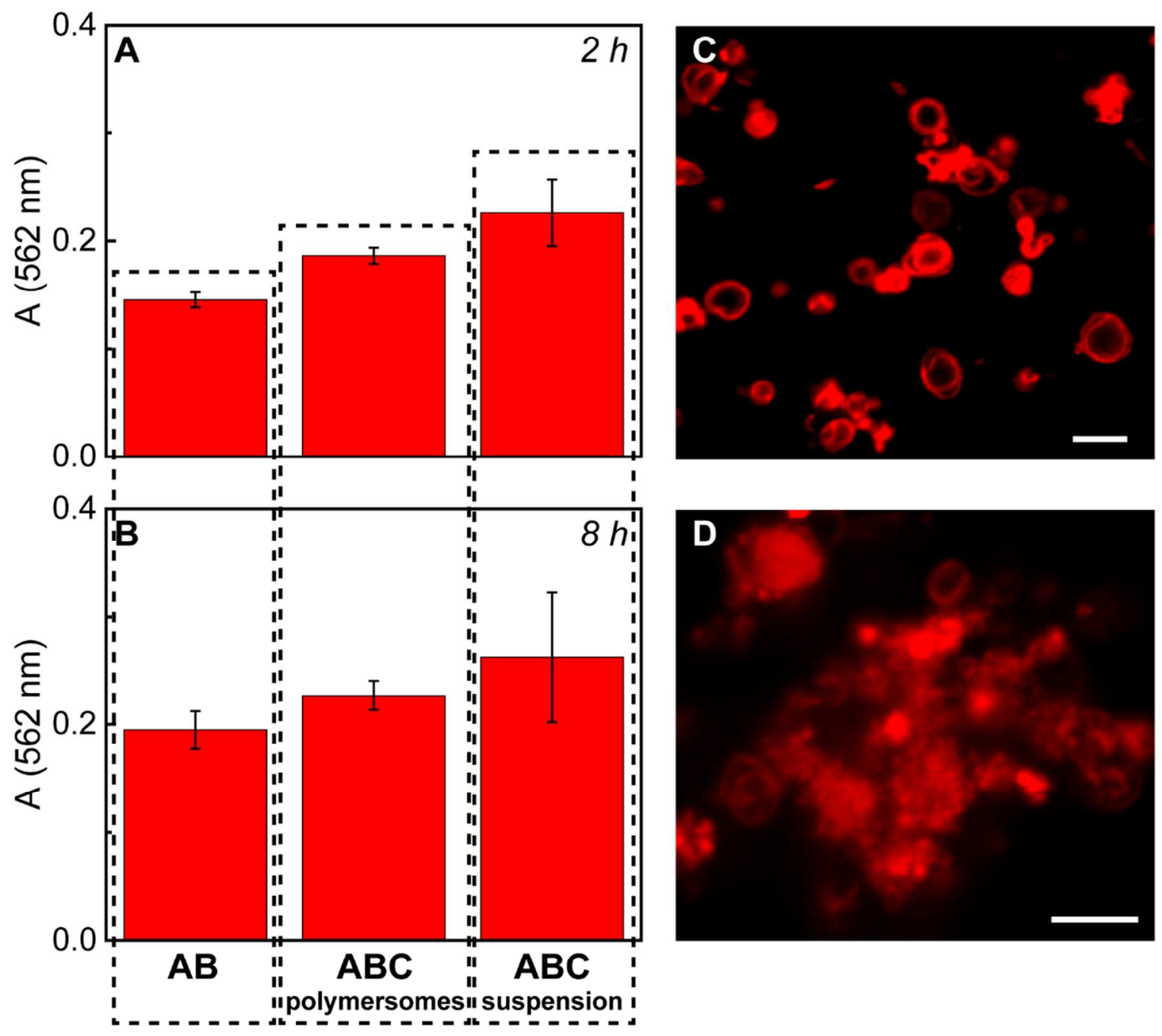

Figure 4. Absorbance $(562 \mathrm{~nm})$ of the supernatant after incubation of $50 \mu \mathrm{lof} 15 \mathrm{mg} \cdot \mathrm{ml}^{-1}$ (1 mM) samples with $400 \mu \mathrm{l}$ of BCA solution at $25^{\circ} \mathrm{C}$. AB: suspension of $\mathrm{PEO}(2.0 \mathrm{~K})-b$ PCL(12.5K); ABC polymersomes: polymersomes formed by $\mathrm{PEO}(2.0 \mathrm{~K})-b$-PCL(12.5K)- $b$ PMOXA(0.3K); ABC suspension: suspension of $\mathrm{PEO}(2.0 \mathrm{~K})-b-\mathrm{PCL}(12.5 \mathrm{~K})-b-\mathrm{PMOXA}(0.3 \mathrm{~K})$. Incubation time: A: $2 \mathrm{~h}$; B: $8 \mathrm{~h}$. LSM images of the aggregates after incubation with BCA solution for C: $2 \mathrm{~h}$ and D: $8 \mathrm{~h}$. Scale bars are $5 \mu \mathrm{m}$.

Based on two independent methods, the data support that PEO- $b$-PCL- $b$-PMOXA with a longer PEO block forms microscale polymersomes with asymmetric membrane containing a 
shorter PMOXA block inside. Asymmetry might be affected by the presence of high molecular weight species in the polymer, but since their concentration is rather low $(\sim 15 \%)$, we do not expect a significant impact on the orientation of the polymer molecules in the membrane of polymersomes. The reactions between polymersomes with reactive groups and fluorescent dyes showed not only the presence of PEO block on the outer surface of polymersomes, but also the absence of PMOXA block outside. The data were also confirmed by BCA assay, which was based on the difference in the chemical composition of PEO and PMOXA blocks. 


\section{Conclusions}

A series of novel amphiphilic asymmetric PEO- $b$-PCL- $b$-PMOXA triblock copolymers with different PCL and PMOXA block lengths was synthesized by the combination of coordination-insertion ring opening polymerization of $\varepsilon$-CL followed by cationic ring opening polymerization of MOXA. The synthesis is free of toxic agents and well-controlled, yielding narrowly dispersed $\left(\bigoplus_{M}<1.25\right)$ polymers with PMOXA block length up to 25 units $(2 \mathrm{kDa})$. We demonstrated the difference in self-assembly behavior of di- and triblock copolymers, and showed that PEO- $b$-PCL- $b$-PMOXA copolymers self-assembled into different microscale structures, including polymersomes, depending on both PCL length and $f$. Self-assembly required $60{ }^{\circ} \mathrm{C}$ due to a semicrystalline nature of the PCL block, which limits the compatibility of the selfassembly process with biomolecules. To overcome this drawback, PCL can be replaced with its amorphous analogue, poly( $\gamma$-methyl- $\varepsilon$-caprolactone) (PMCL), since self-assembly in the case of PEO- $b$-PMCL proceeds under ambient conditions. ${ }^{40-41}$ In addition, PEO- $b$-PMCL- $b$-PMOXA should presumably form nanoscale structures, since the aggregates assembled from PEO- $b$ PMCL have nanometer size range. ${ }^{40}$ Preparation of the nanoscale structures from PEO- $b$-PCL- $b$ PMOXA using method described for PEO- $b-\mathrm{PCL}^{31}$ resulted only in the precipitation of the polymers.

Microscale polymersomes assembled from PEO- $b$-PCL- $b$-PMOXA exhibited an asymmetric orientation of the membrane, which was proven by two independent methods. This creates the possibility to have different functional groups from both sides of the membrane, opening new opportunities towards targeted localization of the desired molecules on the specific side of the polymersome. 


\section{Acknowledgments}

We acknowledge SNSF, NCCR Molecular Systems Engineering, and the University of

Basel for financial support. E. K. acknowledges Samuel Lörcher for fruitful discussions. 


\section{References}

1. $\quad$ Discher, D. E.; Eisenberg, A., Science (Washington, DC) 2002, 297 (5583), 967.

2. Palivan, C. G.; Goers, R.; Najer, A.; Zhang, X.; Car, A.; Meier, W., Bioinspired polymer vesicles and membranes for biological and medical applications. Chemical Society Reviews 2016, 45 (2), 377-411.

3. Nardin, C.; Thoeni, S.; Widmer, J.; Winterhalter, M.; Meier, W., Nanoreactors based on (polymerized) ABA-triblock copolymer vesicles. Chemical Communications 2000, (15), 14331434.

4. Langowska, K.; Palivan, C. G.; Meier, W., Polymer nanoreactors shown to produce and release antibiotics locally. Chemical Communications 2013, 49 (2), 128-130.

5. Tanner, P.; Balasubramanian, V.; Palivan, C. G., Aiding Nature's Organelles: Artificial Peroxisomes Play Their Role. Nano Letters 2013, 13 (6), 2875-2883.

6. Lomora, M.; Garni, M.; Itel, F.; Tanner, P.; Spulber, M.; Palivan, C. G., Polymersomes with engineered ion selective permeability as stimuli-responsive nanocompartments with preserved architecture. Biomaterials 2015, 53, 406-414.

7. Lomora, M.; Itel, F.; Dinu, I. A.; Palivan, C. G., Selective ion-permeable membranes by insertion of biopores into polymersomes. Physical Chemistry Chemical Physics 2015, 17 (24), 15538-15546.

8. Stoenescu, R.; Graff, A.; Meier, W., Asymmetric ABC-triblock copolymer membranes induce a directed insertion of membrane proteins. Macromolecular bioscience 2004, 4 (10), 9305.

9. Blanazs, A.; Massignani, M.; Battaglia, G.; Armes, S. P.; Ryan, A. J., Tailoring Macromolecular Expression at Polymersome Surfaces. Advanced Functional Materials 2009, 19 (18), 2906-2914.

10. Liu, G.; Ma, S.; Li, S.; Cheng, R.; Meng, F.; Liu, H.; Zhong, Z., The highly efficient delivery of exogenous proteins into cells mediated by biodegradable chimaeric polymersomes. Biomaterials 2010, 31 (29), 7575-7585.

11. Liu, Q.; Chen, J.; Du, J., Asymmetrical Polymer Vesicles with a "Stealthy" Outer Corona and an Endosomal-Escape-Accelerating Inner Corona for Efficient Intracellular Anticancer Drug Delivery. Biomacromolecules 2014, 15 (8), 3072-3082.

12. Stoenescu, R.; Meier, W., Vesicles with asymmetric membranes from amphiphilic ABC triblock copolymers. Chemical communications (Cambridge, England) 2002, (24), 3016-7.

13. Wittemann, A.; Azzam, T.; Eisenberg, A., Biocompatible Polymer Vesicles from Biamphiphilic Triblock Copolymers and Their Interaction with Bovine Serum Albumin. Langmuir 2007, 23 (4), 2224-2230.

14. Du, J.; Fan, L.; Liu, Q., pH-Sensitive Block Copolymer Vesicles with Variable Trigger Points for Drug Delivery. Macromolecules 2012, 45 (20), 8275-8283.

15. Mason, A. F.; Thordarson, P., Polymersomes with Asymmetric Membranes Based on Readily Accessible Di- and Triblock Copolymers Synthesized via SET-LRP. ACS Macro Letters 2016, 5 (10), 1172-1175.

16. Matter, Y.; Enea, R.; Casse, O.; Lee, C. C.; Baryza, J.; Meier, W., Amphiphilic PEG-bPMCL-b-PDMAEMA Triblock Copolymers: From Synthesis to Physico-Chemistry of SelfAssembled Structures. Macromolecular Chemistry and Physics 2011, 212 (9), 937-949. 
17. Zhang, W.; He, J.; Liu, Z.; Ni, P.; Zhu, X., Biocompatible and pH-responsive triblock copolymer mPEG-b-PCL-b-PDMAEMA: Synthesis, self-assembly, and application. Journal of Polymer Science Part A: Polymer Chemistry 2010, 48 (5), 1079-1091.

18. Konishcheva, E.; Häussinger, D.; Lörcher, S.; Meier, W., Key aspects to yield low dispersity of PEO-b-PCL diblock copolymers and their mesoscale self-assembly. European Polymer Journal 2016, 83, 300-310.

19. Aoi, K.; Okada, M., Polymerization of oxazolines. Progress in Polymer Science 1996, 21 (1), 151-208.

20. Saegusa, T.; Ikeda, H.; Fujii, H., Isomerization Polymerization of 2-Oxazoline. IV. Kinetic Study of 2-Methyl-2-oxazoline Polymerization. Macromolecules 1972, 5 (4), 359-362.

21. Wiesbrock, F.; Hoogenboom, R.; Leenen, M. A. M.; Meier, M. A. R.; Schubert, U. S., Investigation of the Living Cationic Ring-Opening Polymerization of 2-Methyl-, 2-Ethyl-, 2Nonyl-, and 2-Phenyl-2-oxazoline in a Single-Mode Microwave Reactor $\dagger$. Macromolecules 2005, 38 (12), 5025-5034.

22. Korich, A. L.; Walker, A. R.; Hincke, C.; Stevens, C.; Iovine, P. M., Synthesis, characterization, and star polymer assembly of boronic acid end-functionalized polycaprolactone. Journal of Polymer Science Part A: Polymer Chemistry 2010, 48 (24), 57675774.

23. Schmulbach, C. D.; Hinckley, C. C.; Wasmund, D., Solutions of alkali metals in anhydrous pyridine. Journal of the American Chemical Society 1968, 90 (24), 6600-6602.

24. Hoogenboom, R.; Fijten, M. W. M.; Schubert, U. S., Parallel kinetic investigation of 2oxazoline polymerizations with different initiators as basis for designed copolymer synthesis. Journal of Polymer Science Part A: Polymer Chemistry 2004, 42 (8), 1830-1840.

25. Hoogenboom, R.; Fijten, M. W. M.; Thijs, H. M. L.; van Lankvelt, B. M.; Schubert, U. S., Microwave-assisted synthesis and properties of a series of poly(2-alkyl-2-oxazoline)s. Designed Monomers and Polymers 2005, 8 (6), 659-671.

26. Hoogenboom, R.; Wiesbrock, F.; Huang, H.; Leenen, M. A. M.; Thijs, H. M. L.; van Nispen, S. F. G. M.; van der Loop, M.; Fustin, C.-A.; Jonas, A. M.; Gohy, J.-F.; Schubert, U. S., Microwave-Assisted Cationic Ring-Opening Polymerization of 2-Oxazolines: A Powerful Method for the Synthesis of Amphiphilic Triblock Copolymers. Macromolecules 2006, 39 (14), 4719-4725.

27. Wiesbrock, F.; Hoogenboom, R.; Leenen, M.; van Nispen, S. F. G. M.; van der Loop, M.; Abeln, C. H.; van den Berg, A. M. J.; Schubert, U. S., Microwave-Assisted Synthesis of a 42Membered Library of Diblock Copoly(2-oxazoline)s and Chain-Extended Homo Poly(2oxazoline)s and Their Thermal Characterization. Macromolecules 2005, 38 (19), 7957-7966.

28. Vergaelen, M.; Verbraeken, B.; Monnery, B. D.; Hoogenboom, R., Sulfolane as Common Rate Accelerating Solvent for the Cationic Ring-Opening Polymerization of 2-Oxazolines. ACS Macro Letters 2015, 4 (8), 825-828.

29. Litt, M.; Levy, A.; Herz, J., Polymerization of Cyclic Imino Ethers. X. Kinetics, Chain Transfer, and Repolymerization. Journal of Macromolecular Science: Part A - Chemistry 1975, 9 (5), 703-727.

30. Glassner, M.; D’hooge, D. R.; Young Park, J.; Van Steenberge, P. H. M.; Monnery, B. D.; Reyniers, M.-F.; Hoogenboom, R., Systematic investigation of alkyl sulfonate initiators for the cationic ring-opening polymerization of 2-oxazolines revealing optimal combinations of monomers and initiators. European Polymer Journal 2015, 65, 298-304. 
31. Qi, W.; Ghoroghchian, P. P.; Li, G.; Hammer, D. A.; Therien, M. J., Aqueous selfassembly of poly(ethylene oxide)-block-poly(?-caprolactone) (PEO-b-PCL) copolymers: disparate diblock copolymer compositions give rise to nano- and meso-scale bilayered vesicles. Nanoscale 2013, 5 (22), 10908-10915.

32. Rajagopal, K.; Mahmud, A.; Christian, D. A.; Pajerowski, J. D.; Brown, A. E. X.; Loverde, S. M.; Discher, D. E., Curvature-Coupled Hydration of Semicrystalline Polymer Amphiphiles Yields flexible Worm Micelles but Favors Rigid Vesicles: Polycaprolactone-Based Block Copolymers. Macromolecules 2010, 43 (23), 9736-9746.

33. Zupancich, J. A.; Bates, F. S.; Hillmyer, M. A., Aqueous Dispersions of Poly(ethylene oxide)-b-poly( $\gamma$-methyl- $\varepsilon$-caprolactone) Block Copolymers. Macromolecules 2006, 39 (13), 4286-4288.

34. Jain, S.; Bates, F. S., Consequences of Nonergodicity in Aqueous Binary PEO-PB Micellar Dispersions. Macromolecules 2004, 37 (4), 1511-1523.

35. Wu, D.; Spulber, M.; Itel, F.; Chami, M.; Pfohl, T.; Palivan, C. G.; Meier, W., Effect of Molecular Parameters on the Architecture and Membrane Properties of 3D Assemblies of Amphiphilic Copolymers. Macromolecules 2014, 47 (15), 5060-5069.

36. Jain, S.; Bates, F. S., On the Origins of Morphological Complexity in Block Copolymer Surfactants. Science 2003, 300 (5618), 460-464.

37. Itel, F.; Chami, M.; Najer, A.; Lörcher, S.; Wu, D.; Dinu, I. A.; Meier, W., Molecular Organization and Dynamics in Polymersome Membranes: A Lateral Diffusion Study. Macromolecules 2014, 47 (21), 7588-7596.

38. Schlaad, H.; You, L.; Sigel, R.; Smarsly, B.; Heydenreich, M.; Mantion, A.; Masic, A., Glycopolymer vesicles with an asymmetric membrane. Chemical Communications 2009, (12), 1478-1480.

39. Smith, P. K.; Krohn, R. I.; Hermanson, G. T.; Mallia, A. K.; Gartner, F. H.; Provenzano, M. D.; Fujimoto, E. K.; Goeke, N. M.; Olson, B. J.; Klenk, D. C., Measurement of protein using bicinchoninic acid. Analytical Biochemistry 1985, 150 (1), 76-85.

40. Vangeyte, P.; Jérôme, R., Amphiphilic block copolymers of high-molecular-weight poly(ethylene oxide) and either $\varepsilon$-caprolactone or $\gamma$-methyl- $\varepsilon$-caprolactone: Synthesis and characterization. Journal of Polymer Science Part A: Polymer Chemistry 2004, 42 (5), 11321142.

41. Petersen, M. A.; Yin, L.; Kokkoli, E.; Hillmyer, M. A., Synthesis and characterization of reactive PEO-PMCL polymersomes. Polymer Chemistry 2010, 1 (8), 1281-1290. 


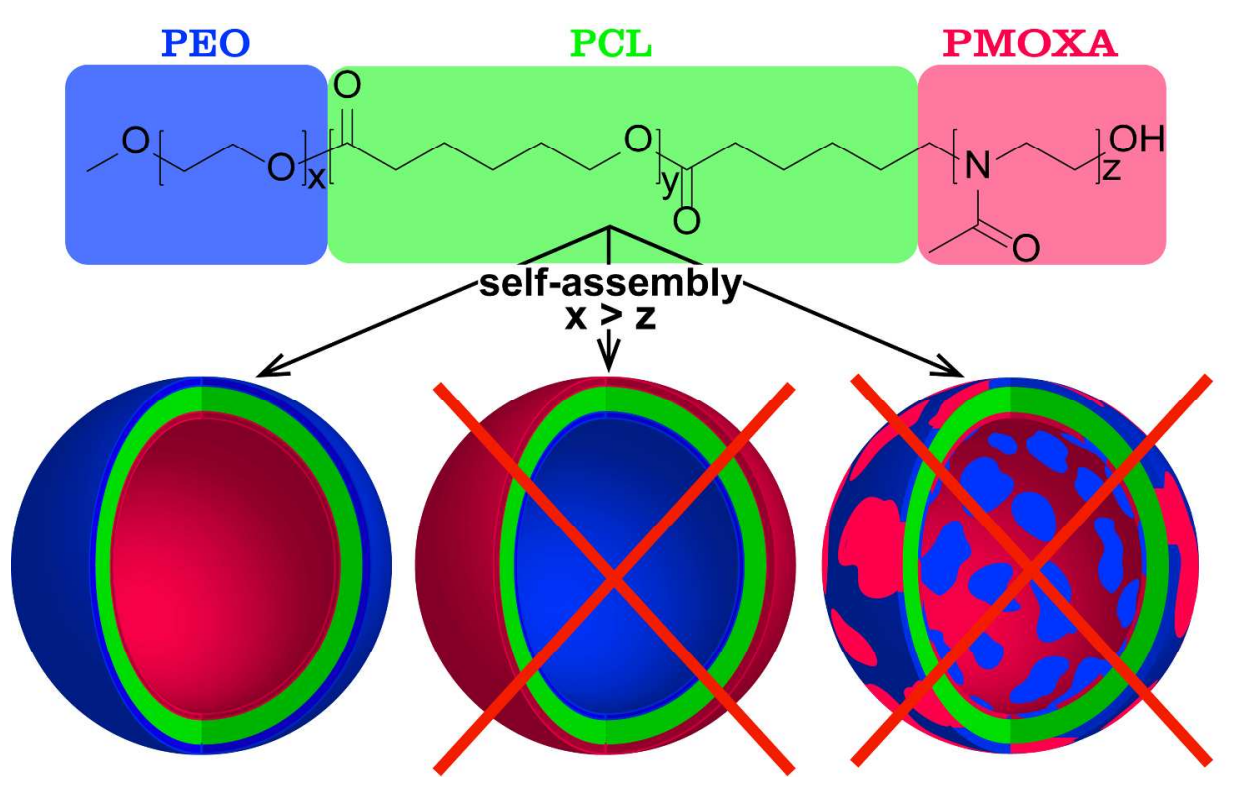

TOC figure

$241 \times 140 \mathrm{~mm}(300 \times 300$ DPI) 


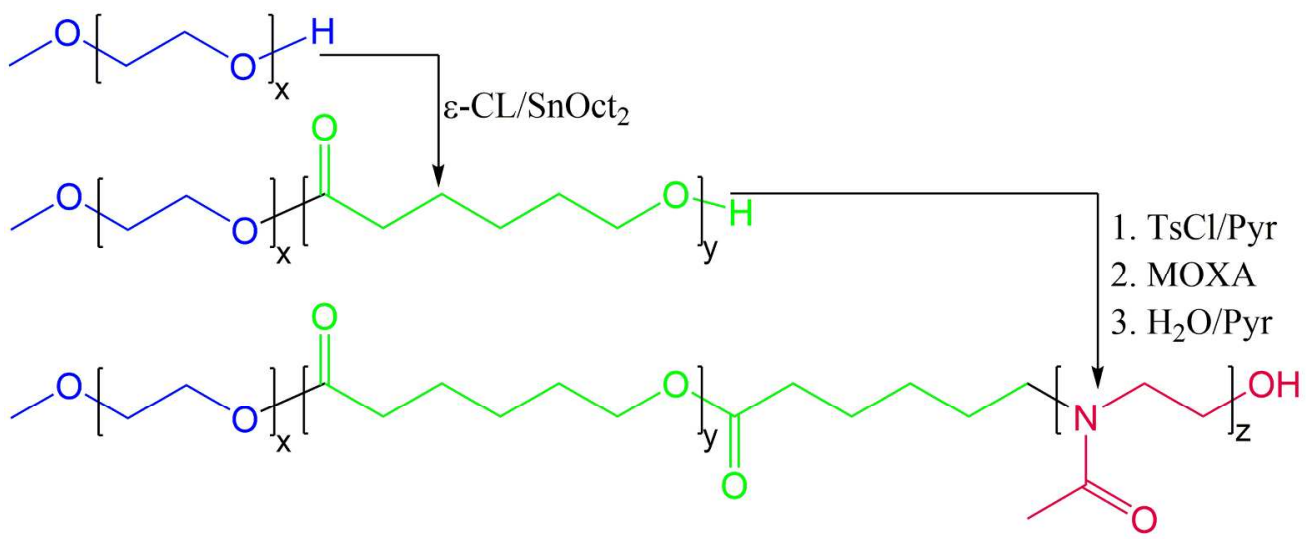

Scheme 1. Synthetic strategy for PEO-b-PCL-b-PMOXA copolymers.

$203 \times 82 \mathrm{~mm}(300 \times 300$ DPI $)$ 
Figure 1. A: representative $1 \mathrm{H} N M R(C D C l 3)$ spectrum of PEO-b-PCL-b-PMOXA triblock copolymer; $B$ : representative GPC (DMF) traces of PEO (blue, $Đ M=1.08$ ), PEO-b-PCL (green, ĐM = 1.08), PEO-b-PCL-OTs (black, ĐM = 1.11), and PEO-b-PCL-b-PMOXA (red, ĐM = 1.14).

$$
208 \times 378 \mathrm{~mm}(300 \times 300 \mathrm{DPI})
$$



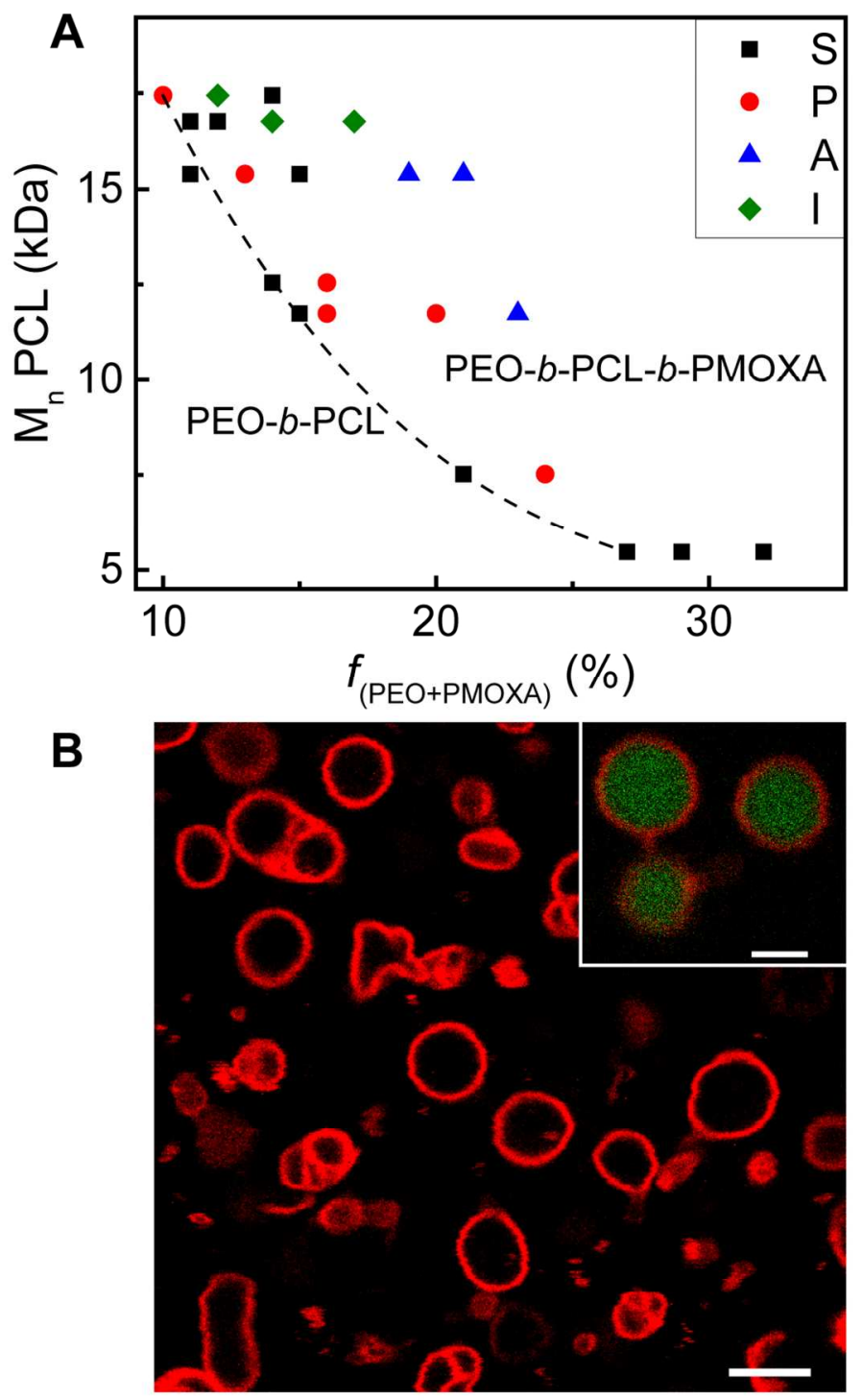

Figure 2. A: Phase diagram of microscale self-assembled structures formed by PEO-b-PCL (points on the dashed line) and PEO-b-PCL-b-PMOXA (points above the dashed line) copolymers using film rehydration method at $60^{\circ} \mathrm{C}$. S - spherical particles, P - polymersomes, A - aggregates, I - irregularly shaped particles. Morphologies were determined qualitatively from LSM images. Most of the systems exhibited mixed morphologies, but to simplify the scheme, only the major component is reported. For more detailed information see Table 1. B: LSM image of polymersomes formed by PEO(2.0K)-b-PCL(12.5K)-bPMOXA(0.3K). Polymersomes were stained with Bodipy 630/650 dye; scale bar is $5 \mu \mathrm{m}$. Inset in the right upper corner represents polymersomes with encapsulated hydrophilic dye calcein; scale bar is $2 \mu \mathrm{m}$. 


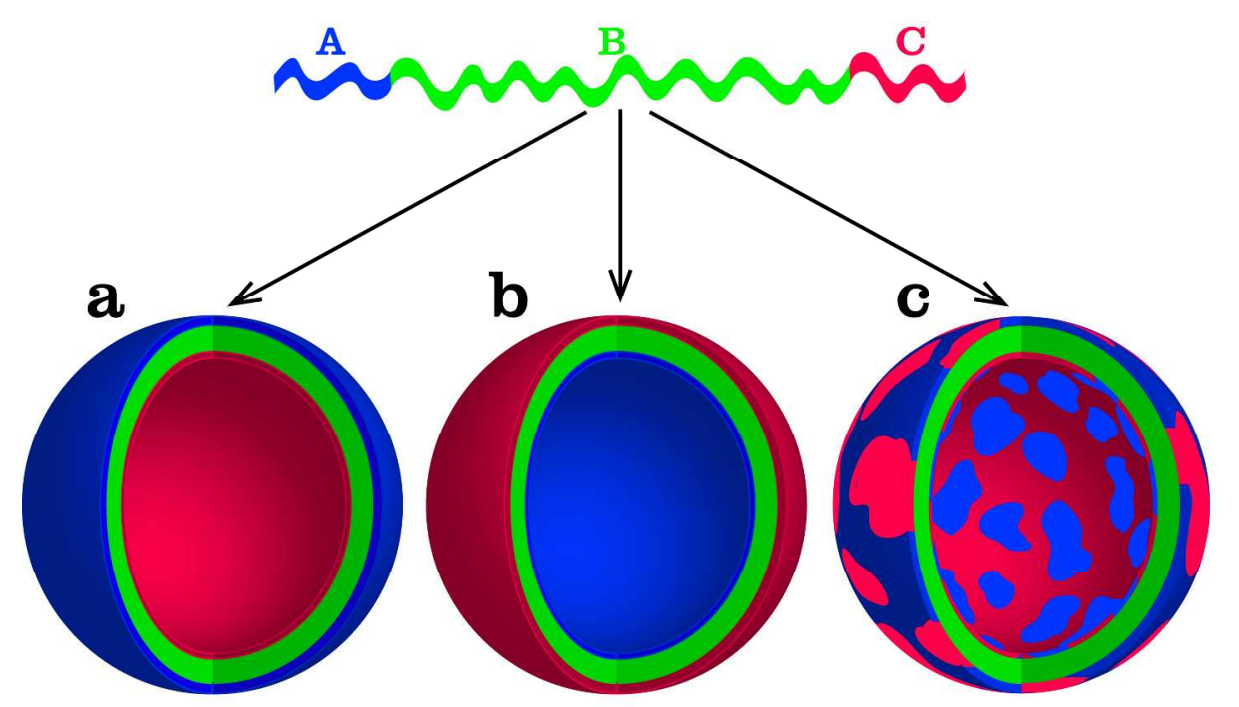

Scheme 2. Possible composition of the membrane of polymersomes formed by ABC copolymer: a: A outside; b: C outside; c: A and C form a mixed membrane.

$241 \times 128 \mathrm{~mm}(300 \times 300$ DPI) 

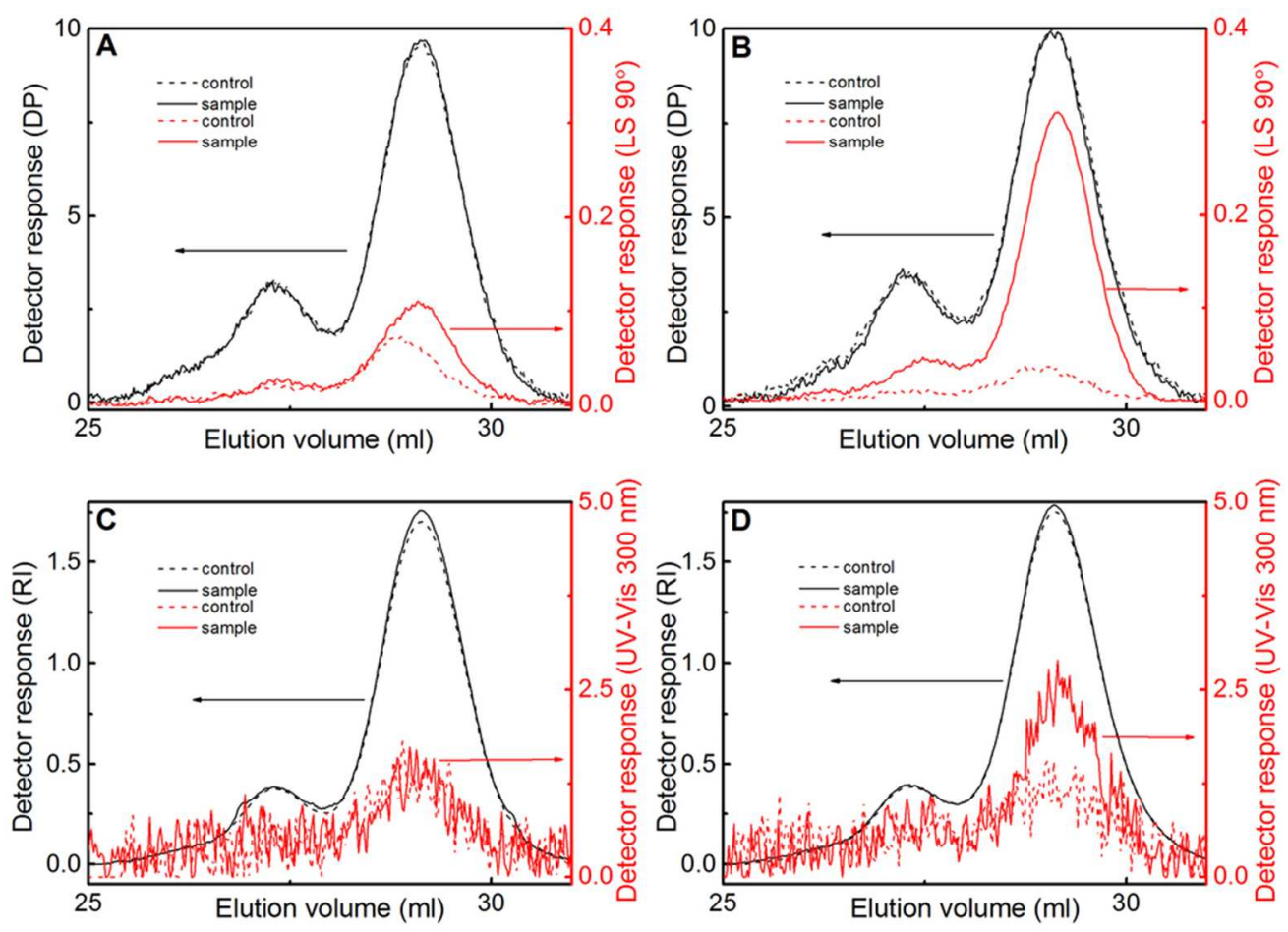

Figure 3. GPC (DMF) traces recorded on DP/LS $90^{\circ}$ (A, B) and RI/UV-Vis (300 nm) (C, D) detectors of a mixture after reaction between alkyne/azide containing polymersomes and azide/alkyne-dye: $A, C: 85 \%$ PEO(2.0K)-b-PCL(12.5K)-b-PMOXA(0.3K) + $15 \%$ PEO(2.0K)-b-PCL(11.7K)-b-PMOXA(0.3K)-Azide + SulfoCy3-Alkyne; B, D: $85 \%$ PEO(2.0K)-b-PCL(12.5K)-b-PMOXA(0.3K) + $15 \%$ Alkyne-PEO(2.0K)-b-PCL(11.4K)b-PMOXA $(0.3 \mathrm{~K})+$ Sulfo-Cy3-Azide. "Controls" were obtained from the reaction mixture which did not contain $\mathrm{Cu}$ (II) complex and sodium ascorbate. "Samples" corresponded to the reaction mixture which contained $\mathrm{Cu}$ (II) complex and sodium ascorbate. The samples for GPC analysis were prepared by removing water from the reaction mixture and dissolving them in DMF ( $20 \mathrm{mM} \mathrm{LiBr})$ to a final concentration of 2 $\mathrm{mg} \cdot \mathrm{ml}-1$ followed by filtration.

$82 \times 59 \mathrm{~mm}(300 \times 300$ DPI $)$ 

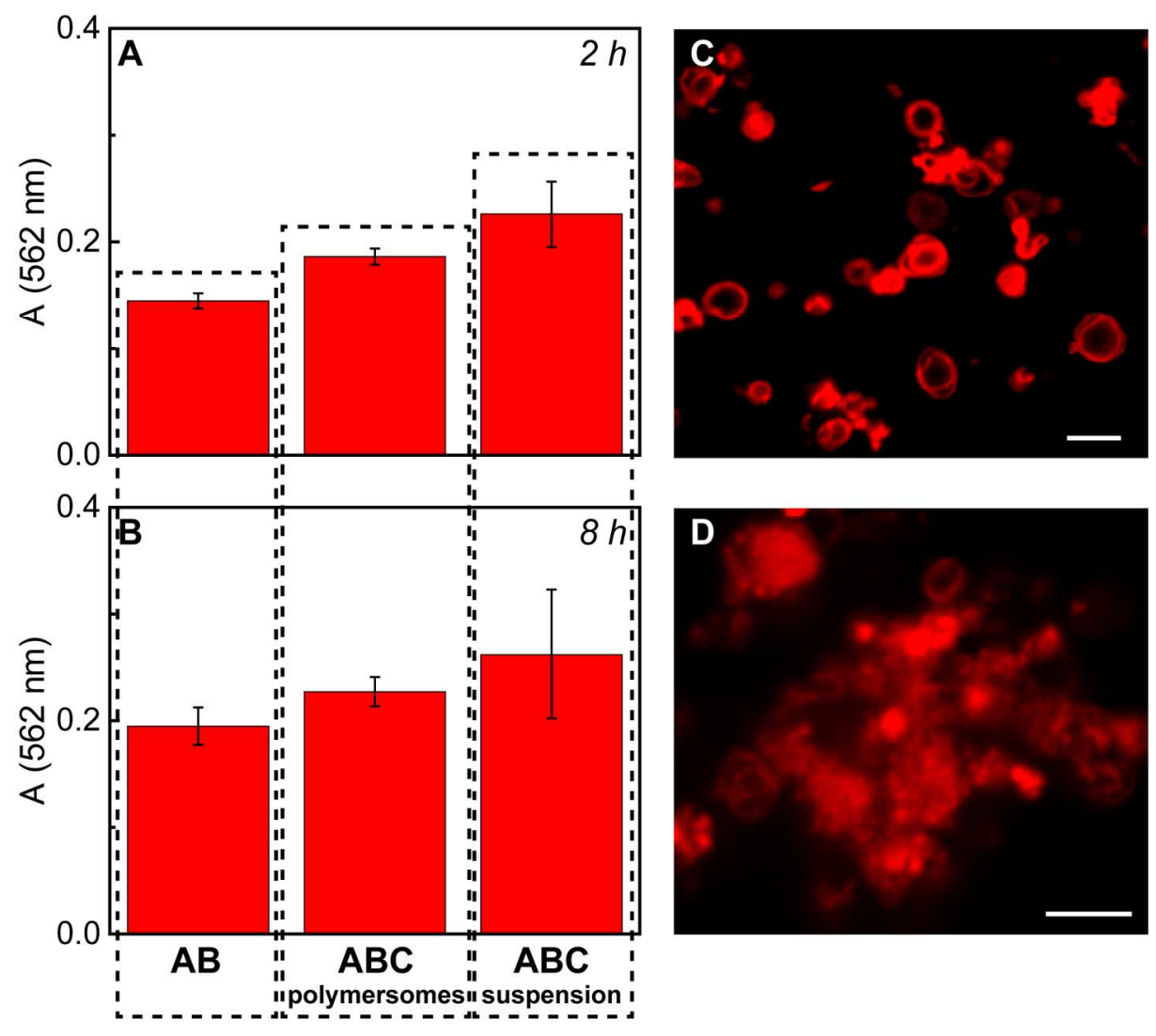

Figure 4. Absorbance $(562 \mathrm{~nm})$ of the supernatant after incubation of $50 \mu \mathrm{l}$ of $15 \mathrm{mg} \cdot \mathrm{ml}-1(1 \mathrm{mM})$ samples with $400 \mu \mathrm{l}$ of $\mathrm{BCA}$ solution at $25^{\circ} \mathrm{C}$. $\mathrm{AB}$ : suspension of $\mathrm{PEO}(2.0 \mathrm{~K})-\mathrm{b}-\mathrm{PCL}(12.5 \mathrm{~K}) ; \mathrm{ABC}$ polymersomes: polymersomes formed by PEO(2.0K)-b-PCL(12.5K)-b-PMOXA(0.3K); ABC suspension: suspension of PEO(2.0K)-b-PCL(12.5K)-b-PMOXA(0.3K). Incubation time: A: $2 \mathrm{~h}$; B: $8 \mathrm{~h}$. LSM images of the aggregates after incubation with BCA solution for C: $2 \mathrm{~h}$ and D: $8 \mathrm{~h}$. Scale bars are $5 \mu \mathrm{m}$.

$171 \times 150 \mathrm{~mm}(300 \times 300 \mathrm{DPI})$ 